\title{
Irrigation Performance Measures: Efficiency and Uniformity
}

\author{
By C. M. Burt, ${ }^{1}$ A. J. Clemmens, ${ }^{2}$ T. S. Strelkoff, ${ }^{3}$ K. H. Solomon, ${ }^{4}$ R. D. Bliesner, ${ }^{5}$ \\ L. A. Hardy, ${ }^{6}$ T. A. Howell, ${ }^{7}$ Members, ASCE, and D. E. Eisenhauer ${ }^{8}$
}

\begin{abstract}
Agstract: It is essential to standardize the definitions and approaches to quantifying various irrigation performance measures. The ASCE Task Committee on Defining Irrigation Efficiency and Uniformity provides a comprehensive examination of various performance indices such as irrigation efficiency, application efficiency, irrigation sagacity, distribution uniformity, and others. Consistency is provided among different irrigation methods and different scales. Clarification of common points of confusion is provided, and methods are proposed whereby the accuracy of numerical values of the performance indicators can be assessed. This issue has two companion papers that provide more detailed information on statistical distribution uniformity and the accuracy of irrigation efficiency estimates.
\end{abstract}

\section{BACKGROUND}

Historically, early irrigation works were typically implemented to ensure human physical survival. In the absence of large populations, industries, and recreation, there was not much competition for water except among neighboring irrigators sharing the same source of water. The chief concern was production of the crop. The problems stemming from control of a source were settled politically, militarily, or diplomatically. The problems of bringing the water from source to plants were solved technically, with ever more and bigger hydraulic structures.

With increasing competition not only among neighboring irrigators but also among agricultural and nonagricultural users of water, the notion of water conservation was born. The idea that crops could do well with limited quantities of water, even better than with unlimited quantities because of waterlogging and salinization of crop lands, suggested a more sophisticated management than traditional practices. At the present time, with irrigation needs often constituting the largest portion of a region's water consumption, and competing users often in a political majority, the need for sagacious use of irrigation water has become paramount.

In design and management of irrigation systems, efficient use of water is now often a major goal, as well as production of the crop. Of course, crop production is paramount to a grower who intends to stay in business, but he or she now looks also at water costs and farm sustainability as well as the potential for pollution of the resource by overirrigating. Users of irrigation water often have to defend their share of the water resource with the argument that it is necessary and wisely used. Different methods for irrigation - surface, sprinkler, mi-

\footnotetext{
${ }^{1}$ Dir., Irrig. Training and Res. Ctr., California Polytechnic State Univ., San Luis Obispo, CA 93407

${ }^{2}$ Res. Hydr. Engr., U.S. Water Conservation Lab., USDA-ARS, 4331

E. Broadway, Phoenix, AZ 85040 .

${ }^{3}$ Res. Hydr. Engr., U.S. Water Conservation Lab., USDA-ARS, 4331

E. Broadway, Phoenix, AZ.

${ }^{4}$ Prof. and Head, BioResource and Agric. Engrg. Dept., California Polytechnic State Univ., San Luis Obispo, CA.

${ }^{5}$ Consulting Engr., Keller-Bliesner, 78 East Center, Logan, UT 84321.

${ }^{6}$ Consulting Engr., H\&R Engr., Inc., 690 Loring Dr., NW Salem, OR 97304.

${ }^{7}$ Agric. Engr., USDA-ARS, Drawer 10, Bushland, TX 79012.

'Prof., Dept. of Biol. Systems Engrg., Univ. of Nebraska, Lincoln, NE 68583 .
}

croirrigation, and so forth-are in competition, with water consumption as well as cost and convenience constituting major factors in the choice of one over another.

Thus, it becomes necessary to quantify the performance of irrigation systems, both on the drawing board, as a design and management criterion, and in the field, as an operating criterion. For over four decades, performance indicators, usually called efficiencies for intuitive appeal and meaning goodness, have been defined differently to account for one factor or another, or in application to one or another irrigation method. Often given the same names, say, irrigation efficiency, they meant different things to different segments of the profession. Needless to say, arguments based on different numerical values for terms having the same name lead to confusion. Another component of goodness, or indication of performance, was recognized, namely, uniformity, reflecting the need for equal treatment of plants in various portions of a field. In the confusion, the two terms were sometimes used interchangeably.

A major contribution to order in the profusion of terms and concepts (more concepts than terms!) was provided by the OnFarm Irrigation Committee of the Irrigation and Drainage Division, American Society of Civil Engineers (ASCE 1978) in their concise paper on uniformity and efficiency. Its very conciseness contributed, however, to the possibility for misinterpretation, and confusion has persisted. Numerous papers addressing uniformity and efficiency have appeared since then, notably Merriam and Keller (1978), Bos (1985), Heermann et al. (1990), and Wolters (1992). The present paper aims to

1. Uniquely relate the necessary minimum number of terms and concepts through precise definitions

2. Provide consistency of definition regardless of the region under consideration: field, farm, project, and so on

3. Provide consistency among different irrigation methods, to allow these to be quantitatively compared

4. Foresee future trends in the profession sufficiently to allow the definitions to survive the test of time

5. Present the available approaches for quantifying the performance measures in specific cases

6. Outline the problems that make numerical evaluation of the performance measures difficult and the results uncertain

7. Propose methods whereby the accuracy of numerical values of the performance indicators can be assessed

The original intent of the task committee was to clearly explain the ASCE (1978) definitions, in detail and without changing them. Nevertheless, it became apparent that some modifications were needed in the equations defining irrigation efficiency $(I E)$, distribution uniformity $(D U)$, and application efficiency $(A E)$. The task committee was reluctant to redefine those terms in view of their long historv of use. but recognized 
the need to improve those definitions in order to avoid confusion and mathematical errors. In addition, two companion papers were written to provide more analytical detail on statistical methods for computing irrigation efficiency, distribution uniformity, and their accuracies (A. J. Clemmens and C. M. Burt, unpublished 1997; A. J. Clemmens and K. H. Solomon, unpublished, 1997).

This paper is not a step-by-step procedure manual for the evaluation of specific irrigation methods; it does, however, present the logic that should be used to guide evaluations. Although this paper emphasizes agricultural terminology and examples, the basic definitions of efficiency and uniformity are also applicable to landscape and turf irrigation.

It is recognized that many of the water quantities used to determine irrigation performance measures are difficult to measure precisely. Our inability to make precise measurements or to separate different water quantities should not alter the definitions of the performance measures. Otherwise, no consistency in performance assessment can be achieved in weighing different irrigation systems or in application to different geographical areas. Furthermore, these definitions will remain pertinent as our ability to measure these quantities improves.

The details in this paper are targeted primarily at irrigation professionals and water rights specialists who must possess a common and solid technical understanding of the concepts of efficiency and uniformity. Many of the figures, tables, and definitions can be used by a wider audience.

\section{Performance Measures}

When water is applied to a crop, various fractions of the total application arrive at various destinations at different stages in their travel [see Fig. 1, drawn from ASCE (1978)].

At the heart of any consideration of irrigation performance is an irrigation-water balance and determination of the fate of various fractions of the total irrigation water applied: how much gets to the crop and how it is distributed among the plants, how much of the remainder is recoverable, how much enters the ground water, surface drainage, and so forth. An important related issue is how adequately crop needs are met. Any water supplied by natural means clearly affects crop needs for irrigation water and is part of the overall water balance, which often must be quantified to determine the irrigation-water balance. However, the irrigation performance measures are based solely on the irrigation-water balance.

Once the fractions of the applied water in their respective destinations are known or estimated, it is useful to lump cer-

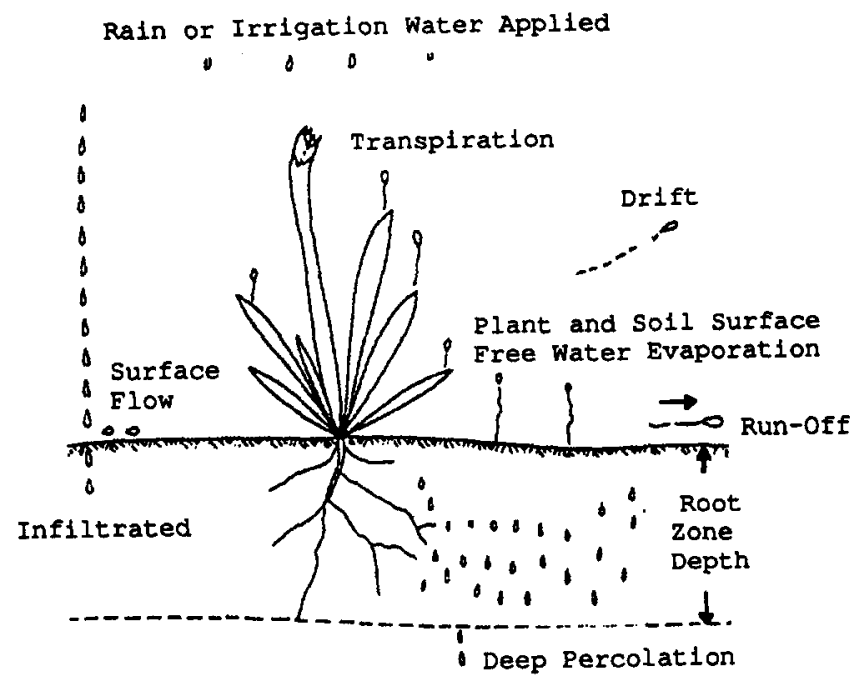

FIG. 1. Disposition of Water in Soll-Crop-Atmosphere System (ASCE 1978) tain categories together, such as beneficial, reasonable, required, useful, and so on to be defined formally later, and to express the summed fraction in each category as a concise measure of performance (e.g., efficiency).

Other concepts such as uniformity and adequacy, too, can be formalized and serve as performance measures, providing information that the others do not.

It should be noted that despite the intuitive relation between efficiency or uniformity and goodness a high value does not necessarily imply good irrigation management. As will be apparent in the following, a high efficiency or uniformity can, under some circumstances, be associated with an unsatisfactory irrigation from one point of view or another. No single term, whatever its numerical value, can fully describe irrigation performance, but a reasonable minimum of terms, taken together, can yield useful information suitable for decision making.

In subsequent sections, irrigation efficiency (retaining the intuitive appeal of the word efficiency), several application efficiencies, irrigation sagacity, distribution uniformity, and adequacy are defined as distinct and useful numerical measures of performance, applicable to various subject areas and to all irrigation methods. But first, water balances are considered from several points of view.

\section{PARTITIONING OF WATER SUPPLIED FROM ALL SOURCES}

The quantitative definition of one or another water use or destination, whether the source is irrigation or natural, depends on the boundaries of the region under consideration. The same water particles identified with one use in one field may travel out of the boundaries of that field and comprise another use elsewhere. This matter will be considered in greater detail following a qualitative description of the various destinations of fractions of the applied water.

There are different ways of classifying the destinations of applied water fractions. One is simply by physical locationin the atmosphere, in the plant, in the soil, and so on-without regard for whether the destination is beneficial or reasonable. This approach is useful for noting all the processes in effect during an irrigation. Another nonjudgmental classification establishes whether the water, once it has arrived at that destination, is recoverable or nonrecoverable, that is, consumed. Judgmental classifications separate beneficial from nonbeneficial uses, reasonable from nonreasonable uses, and so on. These are all viewed in order. Rainfall and natural hydrologic processes must be separated from irrigation water, both entering and leaving the area, so that the performance and effectiveness of the irrigation management can be separated from the overall water management of the crop, farm, and project.

\section{Physical Partitioning of All Water Applled}

Fig. 2 illustrates the partitioning of waters applied to a given region (with three-dimensional boundaries) of soil and crop, for a specified time interval. The various components of the balance, that is, water uses, or destinations, are reviewed next.

\section{Evaporation (E)}

Evaporation, in general, is the conversion of liquid water to vapor. For the purposes of this paper, we exclude from this term any water that has passed through the plant, that is, transpiration, and consider only evaporation from the free surfaces of water in transit (e.g., sprinkler droplets or surface flows, ponds, or puddles), from plant surfaces intercepting irrigation water and from the soil surface interface between the wetted soil matrix below and the atmosphere above. Evaporation rate 


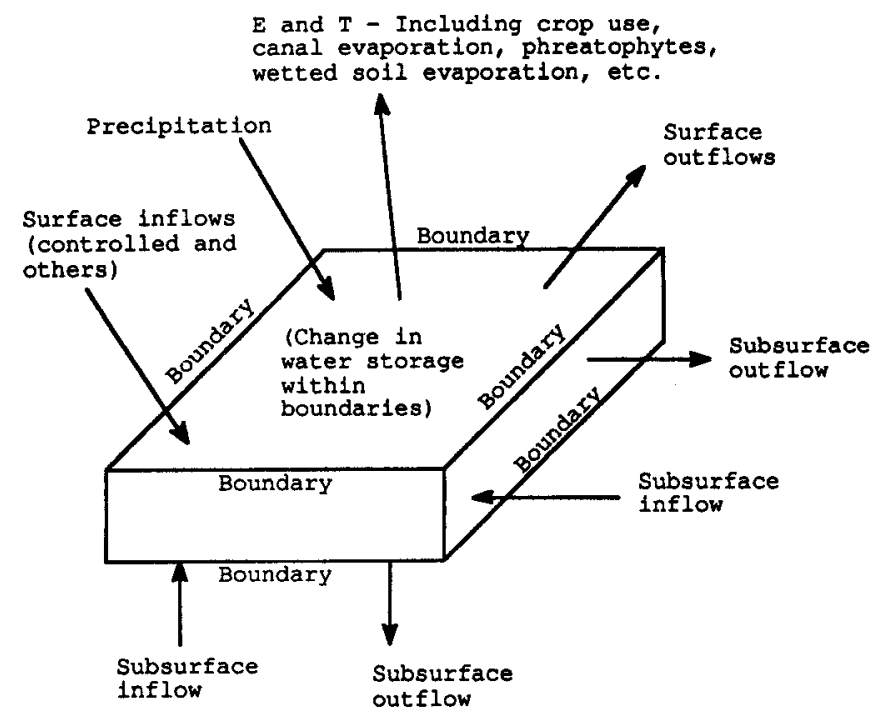

FIG. 2. Components of Simplified Water Balance within Defined Boundaries for Specified Time Interval

is dependent on the water surface area and atmospheric and soil factors. Evaporation can be modified by changing irrigation frequency, irrigation method, mulching, shading, and so forth. Evaporation is subject to advection influences. For example, evaporation from open canals and ditches can have a higher evaporation loss per unit area than a large open body of water.

\section{Transpiration $(T)$}

Transpiration identifies water that has passed through plant stomata and into the atmosphere as vapor. In addition to atmospheric conditions and solar radiation, transpiration is also dependent on evaporation on or near the plants. Transpiration generally decreases as evaporation increases. Micrometeorological factors, mainly temperature and relative humidity, but also wind to a lesser degree, that affect transpiration will be modified by surrounding field conditions to either decrease transpiration when the field is surrounded by similar vegetation or increase transpiration when the field is surrounded by dry fields (called an oasis effect). Plant physiology also plays a role; various plants have different stomatal resistance and sensitivities to soil water availability. Transpiration is reduced if the root-zone soil water is low enough to reduce uptake by roots.

\section{Evapotranspiration (ET)}

Evapotranspiration is the combined process of evaporation from soil and wet plant surfaces and transpiration from plants. The combined ET process is controlled or influenced by soil, crop, irrigation, and atmospheric factors. Evaporation from surrounding areas reduces transpiration, whereas the absence of evaporation from soil or wet plant surfaces increases it. Furthermore, the $E$ and $T$ components are difficult to measure individually, and normally the combined $E T$ is estimated by soil water balance or aboveground energy balance methods.

\section{Crop Evapotranspiration $\left(E T_{c}\right)$}

Crop evapotranspiration is the quantitative amount of $E$ plus $T$ within the cropped area of a field, and which is associated with growing the crop. Fig. 3 illustrates the replacement of some fraction of crop transpiration by evaporation encountered in an irrigation application, plus additional evaporation due to a wet soil or plant surface. $E T_{c}$ is different in the two cases and will vary with the irrigation method and management.

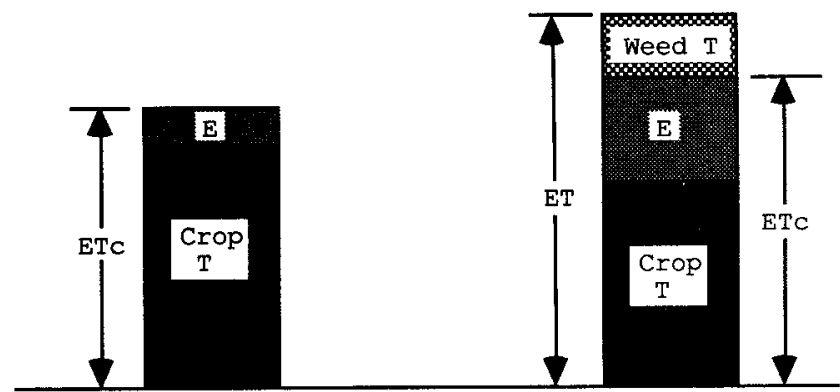

$$
\begin{aligned}
& \text { Well watered crop } \\
& \text { with dry soil and } \\
& \text { plant surfaces (full } \\
& \text { cover, no weeds) }
\end{aligned}
$$

Well watered crop with wet soil and plant surfaces and weeds in between plants
FIG. 3. Tradeoff between Evaporation and Transpiration for Irrigated Crop

Actual $E T_{c}$ values frequently differ from calculated or published values because of differences in irrigation practices (wet versus dry soil; stressed versus unstressed). For most climates part of $E T_{c}$ is supplied by rainfall and part is supplied by irrigation water.

\section{Infiltration}

Infiltration is the process of water movement through the soil surface into the soil matrix. All water that infiltrates through the soil surface is in transit. Some of it enters the plant through the root system immediately, another fraction, up to (and even temporarily exceeding) field capacity of the soil, is temporarily stored as soil water in the root zone. This stored water may also enter the plant, be drawn to the surface and evaporate or, eventually, slowly move down below the root zone.

\section{Deep Percolation (DP)}

Deep percolation is infiltrated water, which moves below the root zone. For a crop with active roots throughout a root zone, almost all of the deep percolation will occur within a short time of the completion of an irrigation. For water stored in a potential root zone (with no active roots), the concept of field capacity is more dynamic, and slow drainage (deep percolation) will occur for several months in a heavy, high clay content soil (Jensen 1972). Excess infiltration supplied by rainfall can be important (e.g., in moving soluble chemicals to the ground water), but it is not included in irrigation-water balances. To separate rainfall from that supplied by irrigation, however, can be difficult.

\section{Runoff (RO)}

Runoff is surface water that leaves the subject region in liquid form. Clearly, what constitutes runoff in a given region can be destined for infiltration and/or transpiration in a downstream region. Surface water captured and reapplied within the subject region is not classified as runoff from the subject area. It may be useful to note its temporary status, in connection with energy use for pumping or degradation in quality, but it does not enter into the water balance or considerations of efficiency if it is captured and reapplied within the boundaries (translocation).

\section{PARTITIONING OF APPLIED IRRIGATION WATER}

The previous section introduced the various processes operating on portions of water applied to a region. When viewed carefully, the region is a volume, with not only a surface area but also with top and bottom boundaries - for example, the 
top of the plant canopy and bottom of the root zone, respectively, for a study with a field-sized boundary. The processes defined imply a concept of destinations reached by water that leaves the region through its boundaries. Further implied is some time interval over which the applications and departures are effected. In previous definitions of irrigation efficiencies, the time period for establishing the destination or function of some portion of the applied water was often left ambiguous. Yet applied water is always in transit, and the category appropriate to a given droplet can change with time. Thus, to judge the performance of an irrigation, the fractions of irrigation water applied through the boundaries of a region and performing the various functions (i.e., reaching various destinations) in leaving the region through its boundaries in a specified time period must be estimated. Any water that does not leave the subject region within the specified time interval is not counted in the performance evaluation.

Various ways of partitioning applied irrigation water are detailed next.

\section{Partitioning of Applied Irrigation Water by Availability for Recovery}

\section{Consumptive Uses}

In a classification alternate to that of the preceding section, irrigation water that ends up in the atmosphere $(E, E T)$ or in the harvested plant tissues (either as molecular water, notably in watermelon or tomatoes, or in organic compounds) is considered irrecoverable, that is, it is consumed.

\section{Nonconsumptive Uses}

These represent any other water quantities that leave the selected region. Nonconsumptive fractions can be reapplied elsewhere, though perhaps degraded in quality by their movement within the boundaries. Runoff, deep percolation, and canal spills are considered such uses.

\section{Judgmental Partitioning of Applied Irrigation Water}

\section{Beneficial Uses}

A beneficial use of water, by definition, supports the production of crops: food, fiber, oil, landscape, turf, ornamentals, or forage. Water consumed in order to achieve an agronomic objective is beneficial. The major beneficial uses are crop ET and water needed for improving or maintaining soil productivity, that is, salt removal (for simplicity, the term "salts" is used to refer to soluble chemicals transported by water). Additional beneficial uses might include water applied for climate control (cooling or frost protection of plants), seedbed preparation, germination of seeds, softening of a soil crust for seedling emergence, and $E T$ from plants beneficial to the crop (wind breaks or cover crops for orchards). Although these additional beneficial uses are generally small, in some situations they constitute a major portion of the beneficial irrigation water.

On the other hand, it would be premature to consider water stored in the root zone, even if intended for subsequent crops, as beneficial. Until it leaves the subject region for one or another destination, it must be considered neutral. Clearly, the time interval selected for the partitioning influences the magnitudes of the fractions computed for the various destinations.

Water that is beneficial to activities other than crop production is not included here, because this paper specifically defines irrigation performance rather than other types of performance related, say, to regional water management. This may differ from local legal definitions of beneficial use. Also, beneficial uses of rainwater are not included as an irrigation beneficial use.

\section{Nonbeneficial Uses}

The irrigation community has a philosophical understanding of what is beneficial, but we sometimes have a practical problem of knowing how to draw the line between beneficial and nonbeneficial uses. For example, it is understood that all irrigations have some nonuniformity, but it is not practical to quantify just how much nonuniformity is unavoidable. Thus, any overirrigation due to nonuniformity is considered nonbeneficial. Although tailwater is necessary for some surface irrigation methods, it is not practical to quantify just how much tailwater is unavoidable. Thus, any uncollected (unrecirculated in the field) tailwater is considered a field-scale nonbeneficial use.

On the other hand, it is practical to quantify (albeit with some uncertainty) the amount of deep percolation necessary for salt removal. Hence, deep percolation in excess of that needed for salt removal (when associated with regular irrigations) has been traditionally considered as a field-scale nonbeneficial use.

Unnecessary evaporation from wet soil outside the cropped area of a field and spray drift beyond the field boundaries have been considered nonbeneficial. Evaporation during regular and reclamation leaching irrigations has been treated differently at various times.

Because no agronomic objective is achieved by irrigating more frequently than needed, we consider evaporation associated with excessively frequent irrigations to be nonbeneficial. Wet soil surface evaporation associated with reclamation leaching and with necessary irrigations are beneficial, since an agronomic objective is achieved during those irrigations.

One might argue that, since the evaporation component of ETiw for some irrigation methods is reduced compared with other methods, all unavoidable wet soil and foliage evaporation associated with even necessary irrigations should be considered nonbeneficial. Unfortunately, with the present state of the art, it is not practical to quantify just how much evaporation is or is not unavoidable. ET has traditionally combined $E$ and $T$ because of inherent difficulties in separating them. Soil evaporation of irrigation water occurs, to some extent, in almost all irrigation situations, even buried drip as commonly practiced, and our traditional concepts and measurements of $E T_{c}$ have included that $E T$ component. Further, some amount of evaporation substitutes for transpiration that would occur in the absence of evaporation.

Therefore, at the present time, because of our practical inability to quantify just how much evaporation is unavoidable, we have elected to include an evaporation component in the beneficial ETiw definitions rather than limiting "ETiw" to something more closely resembling "Tiw."

Weed or phreatophyte $E T$ is considered to be nonbeneficial unless the weeds are an intentional cover crop for purposes such as erosion control (as it impacts on-farm irrigation), improvement of soil structure, or habitat for beneficial insects. Project-scale nonbeneficial uses may include canal seepage, evaporation, and spills.

\section{Beneficial Deep Percolation-Leaching}

Deep percolation, expressed locally as depth $d_{d p}$ (volume per unit area), is a beneficial use when it leaches salts from the root zone to a level required for acceptable crop production. One must look at crop salt tolerances and soil salt accumulation throughout a whole crop rotation, not just based on the current crop. There are some additional cases in which deep percolation is an inevitable result of pursuing an agronomic objective, such as chemigating right after a rain or using sprinklers for frost control after the soil has already been filled 
to field capacity by rainwater. These would be considered beneficial uses.

Leaching from rainfall is not included in this irrigation-related definition. In nonarid climates, separating rainfall leaching from beneficial deep percolation of irrigation water is difficult.

For regular irrigation practices, the required beneficial deep percolation $d_{\text {rbdp }}$ at any location in a field is the amount of infiltrated water necessary to maintain (or reclaim) soil salinity levels below the threshold level at which crop yields are decreased (relative to the maximum). Expressed as a depth (for this discussion of leaching, the lowercase $d$ is used to represent a local depth and, $D$, below, as an average depth over the field), it represents the volume required per unit field area. If all locations within the subject region have an equal requirement, then the local requirement is equal to the average requirement $D_{r b d p}$, simply the total volume required for this purpose divided by the total area.

The volume of water in beneficial deep percolation is the integral over the subject region of $d_{b d p}$, defined as the contribution of local infiltration to $d_{r b d p}$. The average depth of $D_{b d p}$ (volume divided by subject area) is always less than or equal to $D_{\text {rbdp }}$.

\section{Nonbeneficial (Excess) Deep Percolation}

If the actual depth of deep percolation at a given location $d_{d p}$ is more than the required beneficial leaching depth $d_{r b d p}$, that which is in excess of the requirement is nonbeneficial, that is, $d_{n b d p}=\max \left(0,\left[d_{d p}-d_{r b d p}\right]\right)$.

The integral over the subject region of this excess, divided by the area, is the average depth of nonbeneficial deep percolation, $D_{n b d p}$. While the inequality, $D_{d p}>D_{r b d p}$, can result from variations in the requirement over the subject area, it is usually caused by overirrigation over the entire area, or locally because of nonuniform application, that is, specifically, from

- Excessive irrigation (duration of irrigations is excessive)

- Nonuniformity of infiltration caused by the irrigation system, or by spatial variability in soil properties

- Preferential flow of water through cracks in the root zone or other nonhomogeneities in soil structure

As noted, with a nonuniform distribution of infiltrated water, there can be localized areas of deep percolation in excess of leaching requirements, even though the total volume of deep percolation is less than that required for uniform leaching of salts. Figs. 4 and 5 illustrate the relationship between actual and required deep percolation for a nonuniform application over a field having a uniform leaching requirement $\left(d_{r b d p}=\right.$ $\left.D_{r b d p}\right)$. Fig. 4 shows an overirrigated field.

Fig. 5 shows a deficit irrigation. Although in some portions

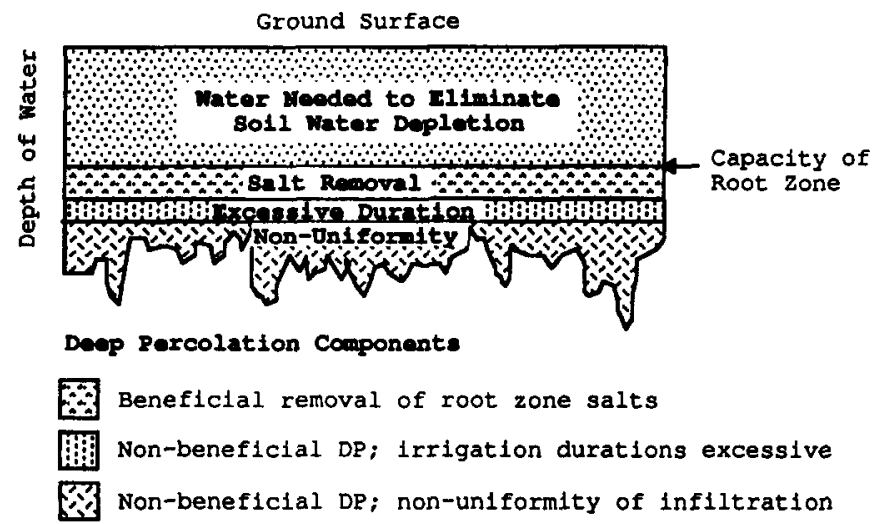

FIG. 4. Overirrigated Field: Beneficial and Nonbeneficial DP

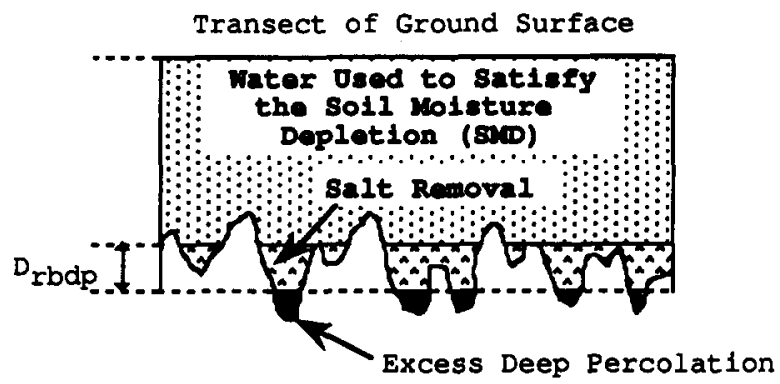

FIG. 5. Deficit Irrigation Nonbeneficial $D P$

of the field the soil water replacement is insufficient to refill the soil water depletion, other portions have more deep percolation than that required for salt leaching. For illustrative purposes, variation in infiltrated depth transverse to the page is not shown. The various fractions are identified by shading and cross-hatching, while the depths shown are volumes per unit field area.

Note that

$$
D_{b d p} \leq D_{r b d p}
$$

regardless of the amount of deep percolation, even if

$$
D_{d p}>D_{r b d p}
$$

Further, it is entirely possible that

$$
D_{n b d p}>0
$$

even if

$$
D_{d p}<D_{r b d p}
$$

\section{Reasonable Uses}

In the context of irrigation performance, all beneficial uses are considered to be reasonable uses. Nonbeneficial uses are reasonable if they are justified under the particular conditions at a particular time and place. Due to physical, economic or managerial constraints, and various environmental requirements, some degree of nonbeneficial use (as already defined) is generally reasonable. Many water rights allocations consider both "reasonable and beneficial use."

Economics, weather uncertainties, and physical limitations of irrigation systems all play a role in determining the "reasonable" range of performance. One area of controversy has been the classification of agricultural runoff into wetlands when these wetlands provide desirable wildlife habitat. That water may be beneficial to the ecosystem in the wetland, but it would not be considered here as beneficial to agricultural production. In such a case the runoff would be reasonable but nonbeneficial in terms of irrigated agricultural production.

Reasonable but nonbeneficial deep percolation can occur because of uncertainties that farmers face when deciding when and how much to irrigate. Examples of common uncertainties include estimates of the actual soil moisture depletion, crop coefficients, reference evapotranspiration measurement of the inflow rates, estimates of advance times and infiltration depths for surface irrigations, necessary leaching requirements for salt control, and on/off times for water deliveries from irrigation districts.

\section{Unreasonable Uses}

As defined here for measuring irrigation performance, unreasonable uses are nonbeneficial uses that, furthermore, are not reasonable; that is, they are without economic, practical, or other justification. It is assumed that if water was used by the 


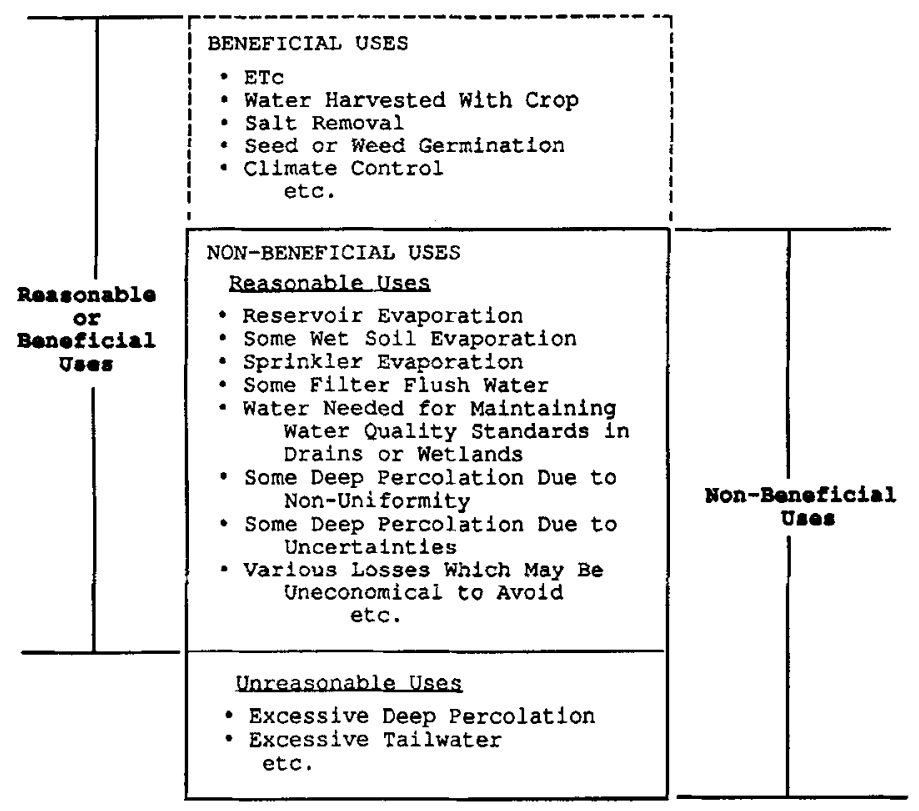

FIG. 6. Some Amount of Nonbeneficial Loss May Be Reasonable

crop, then, from an irrigation standpoint, it was both beneficial and reasonable. From a regional water management perspective, agricultural beneficial uses could be judged unreasonable if, because of climatic or soil factors, it is not reasonable to grow the particular crop benefiting from the irrigation water. That particular argument is beyond the scope of irrigation performance determinations.

The terms "reasonable" (and thus "sagacious") and "unreasonable" may, in some cases, be beyond science since they are judgmental, and may be site and time specific. But, they should not be considered to be beyond engineering since engineering practice usually considers constraints, economics, tradeoffs, value judgments, and different objectives. Fig. 6 tabulates representative beneficial, nonbeneficial, reasonable, and unreasonable uses.

\section{Water Partitions, Balances, and Destination Diagrams}

The information provided by the water-use diagram of Fig. 1 or the partition diagram of Fig. 6 can also be organized into the form of a water balance as in Fig. 2, which emphasizes the concept of subject region boundary. As noted earlier, the boundaries of the region being discussed and an associated transit-time period must be clearly defined if partition fractions are to be properly quantified. For example, deep percolation from fields on the upslope areas of an irrigation project may appear as a high water table in downslope areas of the same project. That high water table may contribute to the $E T_{c}$ in the downslope areas. In that case, the on-farm deep percolation can be high, but if that water is used within the same irrigation project, the fraction of nonbeneficial deep percolation for the project can be lower than any single on-farm value. The overall beneficial use within a river basin is often very high, as runoff or deep percolation from one project is used by other irrigation projects downstream. Any water recirculated within a boundary is, by definition, not an outflow.

Water-destination diagrams provide a convenient means of representing the distribution of applied water. They can take the form either of Figs. 4 and 5, which show variation with location, or of Fig. 7, which shows an ordered variation with field area (for the same infiltration data as plotted in Fig. 5).

In the case of Fig. 7, infiltration values are sorted in decreasing order and are plotted against a corresponding fraction of field area. There is no indication in this diagram as to where,

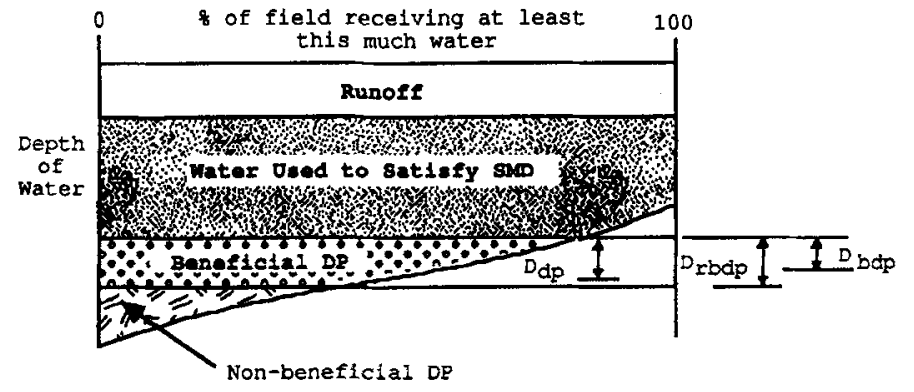

FIG. 7. Irrigation Water Destination Diagram

in the field, a particular value of infiltration occurred. Knowledge of location of deficits, for example, can be used to suggest changes in system operation. On the other hand, sorted distributions graphically show the partitioning of infiltration. Runoff volume in Fig. 7 is shown across the top of the diagram as an equivalent uniform depth (volume divided by subject area). Other losses (spray drift, e.g.) could have been shown in the same way.

\section{PERFORMANCE INDICATOR DEFINITIONS}

Partitioning of applied irrigation water underlies the evaluation of certain performance indicators, notably, efficiencies. Expressed as percentages, these are fractions of the irrigationwater volume that are destined for certain functions. Certain of these efficiencies are impossible to define without careful specification of subject region and time period. Others, by virtue of built-in assumptions, can avoid these issues. The different efficiencies have different purposes and should be carefully differentiated.

Other indicators are more properly expressed as ratios and address concepts such as uniformity of water distribution within a field. A summary of various performance indicators is found in Table 1.

\section{Irrigation Efficiency, IE}

The definition of irrigation efficiency, $I E$, is

$$
\begin{aligned}
I E= & \frac{\text { vol. irrig. water beneficially used }}{\text { vol. irrig. water applied }-\Delta \text { storage of irrig. water }} \\
& \times 100 \%
\end{aligned}
$$

The denominator in (1) represents the total volume (beneficial plus nonbeneficial uses) of irrigation water that leaves the boundaries (outflow $=$ applied $-\Delta$ storage). These volumes leave within a specified time interval (e.g., interval from just before an irrigation to just before the next irrigation, or, possibly, an entire season). If, at the end of the time period, the water contained within the designated region is the same as it was at the start, $\Delta$ storage of irrigation water $=0$, and all of the water applied has left the region-in crop ET, runoff, deep percolation, and so forth. In this way water temporarily stored in the root zone for use outside the specified time interval is not counted-neither adding to the beneficial uses nor subtracting from them; the water remains neutral until such time as it leaves the subject area, one way or another.

The phrase "irrigation water" excludes water applied naturally to the crop, natural precipitation, or rise in the water table, for example. It is possible, without loss of generality, to replace volume, in numerator and denominator, by depth, with the understanding that depth is simply volume divided by area (of field, far, project, etc.). The relationship between $I E$ and beneficial nonbeneficial uses is illustrated in Fig. 8.

The most common misuse of $I E$ is the improper definition of beneficial uses. On the one hand, theoretical beneficial uses 
TABLE 1. Irrigation Performance Indlcators and Their Application

\begin{tabular}{|c|c|c|c|}
\hline $\begin{array}{l}\text { Indicator } \\
\text { (1) }\end{array}$ & $\begin{array}{l}\text { Boundaries } \\
\text { (2) }\end{array}$ & $\begin{array}{l}\text { Time covered } \\
\text { (3) }\end{array}$ & $\begin{array}{l}\text { Other } \\
\text { (4) }\end{array}$ \\
\hline Irrigation efficiency, IE (\%) & $\begin{array}{l}\text { Field, farm, district, project, or } \\
\text { basin }\end{array}$ & $\begin{array}{l}\text { Time interval (between two dates } \\
\text { such as a complete irrigation } \\
\text { season). }\end{array}$ & $\begin{array}{l}\text { Only measured after fact; makes no assump- } \\
\text { tions of future beneficial use. For defined } \\
\text { time interval, requires accurate assess- } \\
\text { ment of what portion of irrigation water } \\
\text { was ultimately beneficially used. Does } \\
\text { not assume uniform water requirement or } \\
\text { use across field. Values depend on start } \\
\text { and end times chosen. }\end{array}$ \\
\hline $\begin{array}{l}\text { Irrigation consumptive use coeffi- } \\
\text { cient, ICUC (\%) }\end{array}$ & $\begin{array}{l}\text { Field, farm, district, project, or } \\
\text { basin. }\end{array}$ & Time interval. & Quantifies unrecovered water. \\
\hline Irrigation sagacity, IS (\%) & $\begin{array}{l}\text { Field, farm, district, project, or } \\
\text { basin. }\end{array}$ & Time interval. & $\begin{array}{l}\text { Includes the concept of reasonable use as } \\
\text { well as beneficial use. }\end{array}$ \\
\hline $\begin{array}{l}\text { Distribution uniformity, } D U \\
\quad \text { (ratio) }\end{array}$ & $\begin{array}{l}\text { Field-wide, but sometimes applied } \\
\text { to a smaller unit, for example, } \\
\text { a single furrow, area between } \\
\text { four sprinklers, or lateral. }\end{array}$ & One irrigation event. & \\
\hline Application efficiency, $A E(\%)$ & Field or smaller unit. & One irrigation event. & $\begin{array}{l}\text { Usually assumes uniform target water depth } \\
\text { across field. Implicit assumption that all } \\
\text { water destined for beneficial use will ulti- } \\
\text { mately be utilized beneficially. }\end{array}$ \\
\hline Adequacy, $A D$ (ratio) & Field or smaller unit. & One irrigation event. & $\begin{array}{l}\text { Provides estimate of adequacy of irrigation } \\
\text { (underirrigation, proper timing, or overir- } \\
\text { rigation). Usually assumes uniform target } \\
\text { water depth across field, just as } A E \text { does. }\end{array}$ \\
\hline $\begin{array}{l}\text { Potential application efficiency, } \\
\qquad P A E(\%)\end{array}$ & Field or smaller unit. & One irrigation event. & $\begin{array}{l}\text { Provides estimate of what level of } A E \text { is } \\
\text { possible, assuming proper timing of irri- } \\
\text { gation event and accounting for } D U \text { and } \\
\text { unrecovered surface losses (evaporation } \\
\text { and runoff). Usually assumes uniform } \\
\text { target water depth across field, just as } A E \\
\text { does. }\end{array}$ \\
\hline
\end{tabular}

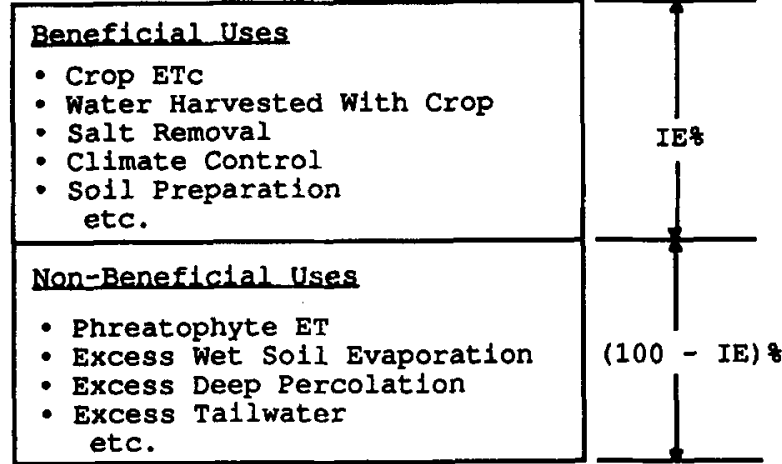

FIG. 8. Irrigation Efficiency (IE) Quanthles Division of Irrigation Water Uses into Beneficial and Nonbeneficial

are often cited instead of actual beneficial uses. On the other, water that satisfies several beneficial uses (e.g., both frost protection and seed germination may become available to satisfy plant $E T$ ) should not be double-counted. These misuses of $I E$ do not negate its importance in reflecting the needs of a sustainable, viable irrigated agriculture, but merely underscore the care with which the terms should be evaluated.

\section{Irrigation Consumptive Use Coefficient, ICUC}

The irrigation consumptive use coefficient (introduced by Jensen 1993) is now defined as the ratio of volume of irrigation water consumptively used to the total volume of irrigation water that has left the region, both in a specified period of time and expressed as a percentage

$$
\begin{aligned}
I C U C= & \frac{\text { vol. irrig. water consumptively used }}{\text { vol. irrig. water applied }-\Delta \text { storage irrig. water }} \\
& \times 100 \%
\end{aligned}
$$

\begin{tabular}{|c|c|}
\hline $\begin{array}{l}\text { Consumptive Uses } \\
\text { - Crop ETc } \\
\text { - Phreatophyte ET } \\
\text { - Sprinkler Evap. } \\
\text { - Reservoir Evap. } \\
\text { - Wet Soll Evap. } \\
\text { - Water Harvested } \\
\text { With Crop } \\
\text { etc. }\end{array}$ & $\begin{array}{l}\text { Non-Consumptive Uses } \\
\text { - Water for Leaching } \\
\text { - Excess Deep Perc. } \\
\text { - Runoff } \\
\text { - Spill } \\
\text { etc. }\end{array}$ \\
\hline
\end{tabular}

Like $I E, I C U C$ can be used on any geographic scale-proj-
FIG. 9. Irrigation Consumptive Use Coefficlent (ICUC) Quantifles Division of Irrigation Water into Consumptive and Nonconsumptive Uses

ect, district, farm, or field. At the project scale, for example, the total project outflow of liquid water (surface and subsurface) in the specified time period that originated through irrigation is $(100-I C U C) \%$ of the irrigation water supplied to the project (surface and subsurface), less the change in storage of the irrigation water. Fig. 9 illustrates the relationship between consumptive and nonconsumptive uses and the ICUC.

Water used for salt control may become unsuitable for direct irrigation use due to its high salinity. However, that unsuitability is different from consumption. It may be made reusable for irrigation by blending with fresh water or reverse osmosis. It may also be suitable for municipal or industrial usage. A decision that drainage water is "consumed" requires a decision based on downstream water usage and treatment, which is inconsistent with the definitions that focus on usage within stated boundaries. Debates on how to treat degraded return flows point out the difficulties of using a limited number of performance indicators to adequately describe all conditions.

ICUC has sometimes been incorrectly used as an estimate of $I E$. Fig. 10 illustrates the differences between these two terms. 


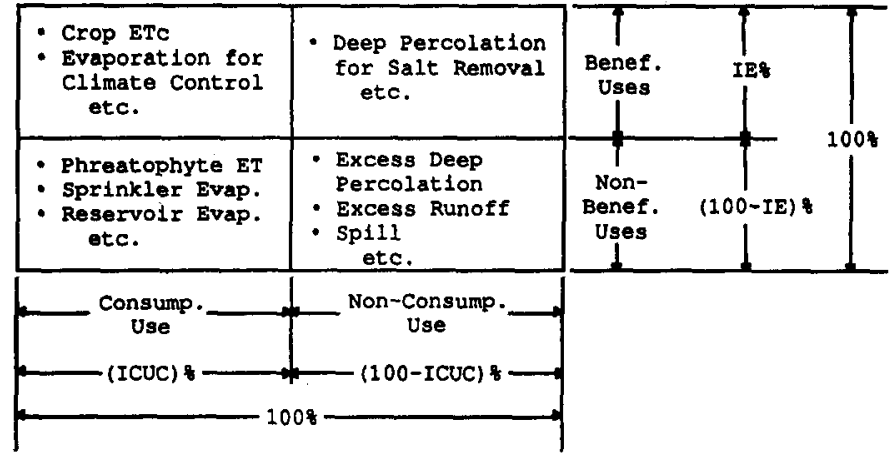

FIG. 10. Division between Consumptive and Nonconsumptive Uses is Distinct from Division between Beneficlal and Nonbeneficial Uses

The International Commission on Irrigation and Drainage (Bos 1985; ICID 1995) has developed a series of irrigation performance measures. The nature of these definitions suggests subdividing performance according to each component of an irrigation project (e.g., project, conveyance, distribution, farm efficiency). These terms deal strictly with consumptive and nonconsumptive uses and are thus similar to the irrigation consumptive use coefficient, ICUC. They do not differentiate between nonbeneficial and beneficial consumptive uses and, therefore, are limited to hydrologic balances and management of irrigation return flows; they do not necessarily represent an accurate picture of irrigated agriculture benefits and performance.

\section{Irrigation Sagacity, IS}

While $I E$ is a useful term for comparison, from the societal and even a grower's point of view, it can be incomplete. Other benefits may accrue to society from water used for irrigation, even a portion not used by the plants, for example, to support riparian wildlife. Or, from another standpoint, it may well be prudent for a grower to apply some water that is not directly used by the crop, that is, unavoidable losses. These concepts of reasonable use, detailed in the preceding section, suggest a new term to complement irrigation efficiency, namely, irrigation sagacity, $I S$, introduced by Solomon (unpublished memorandum, 1993) and now defined:

$I S=\frac{\text { vol. irrig. water benef. and/or reason. used }}{\text { vol. irrig. water applied }-\Delta \text { storage irrig. water }}$

$$
\times 100 \%
$$

It is not suggested that $I S$ be used in place of $I E$; rather, with clear definitions of both offered, either or both can be used as appropriate. Fig. 11 illustrates the difference between the two.

\section{Distribution Uniformity, $D U$}

In addition to the issue of how well the applied water is used is the important issue of how uniformly this water is distributed to the crop (or the soil, for a preirrigation). A nonuniform distribution not only can deprive portions of the crop of needed water, but, furthermore, can overirrigate portions of a field, leading to water-logging, plant injury, salinization, and transport of chemicals to the ground water (Solomon 1983). Distribution uniformity, $D U$, is defined here as a measure of the uniformity with which irrigation water is distributed to different areas in a field.

Furthermore, to express $D U$ solely in terms of postirrigation infiltrated depth, as is commonly done, ignores both water intercepted by the canopy and that evaporation that reduces crop transpiration, fractions of the distributed water, which never

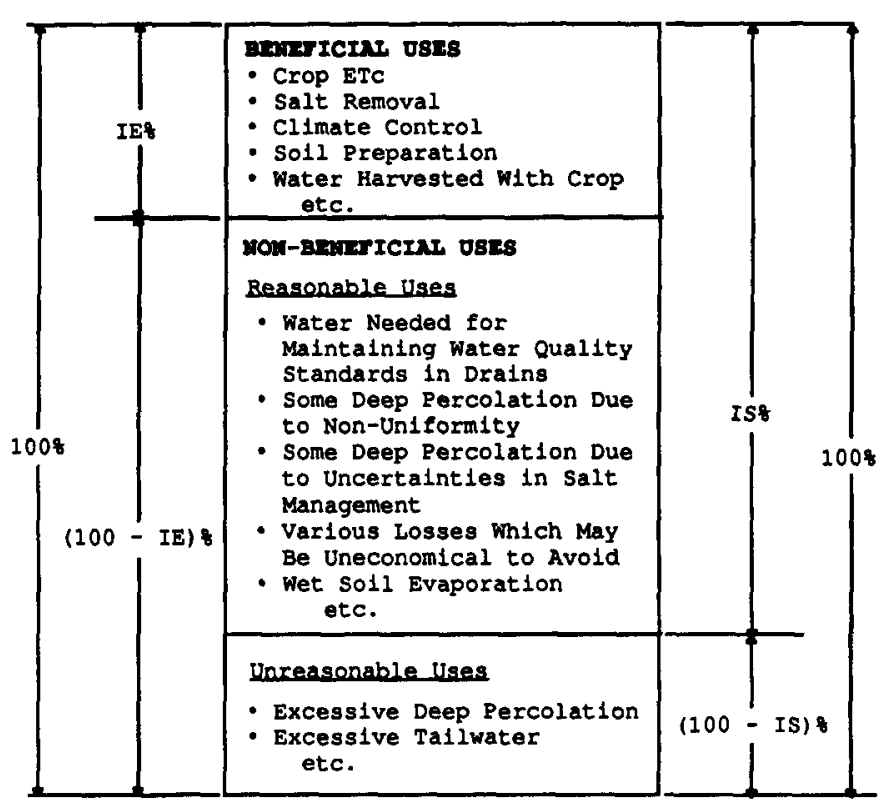

FIG. 11. Irrigation Sagacity (IS) Is Better Measure of Prudent Water Use Than Irrigation Efficiency (IE)

contribute to infiltrated depth. For light applications by sprinklers, for example, incorporation of these fractions could significantly improve the estimate of true $D U$ as opposed to a $D U$ calculated from soil water measurements after the event. Additionally, the field methods of evaluating sprinkler pattern overlap almost always use catch containers located above the canopy, and measure intercepted, in addition to infiltrated, depths. Thus for defining $D U$, the term accumulated water is used here to include the infiltration, canopy interception, and reduction of transpiration during irrigation.

Before $D U$ can be defined for a distribution, the distribution itself must be carefully defined, in order that it be truly universal, that is, applicable to all crops - trees, vines, vegetables, field crops, turf, and so forth. The formally stated distribution of water over a field should incorporate concepts both of the totality of field elements requiring water and of element scale. An element is the smallest area in the field that requires water, but within which the variation of distributed water is not important. That is, if all the elements are the same size, the distribution of water applied over the field would be satisfactorily defined by a listing of values of irrigation water depth for every element. Additional detailing of how the water applied to an element is distributed over that element has no bearing on defining $D U$.

Studies in vineyards and orchards have shown that, in the vicinity of a plant, root growth concentrates in those areas where soil water is available. Thus, the details of distribution in the vicinity of a plant, provided that it remains more or less constant over a growing season, may not be important, and the element scale would be taken to be the region occupied by the roots - already, or potentially - of one plant.

With field crops the same concept applies, except that, in this case, the element over which one can conveniently measure the volume accumulated is typically much larger than that occupied by a single plant. The area of measurement, then, is accepted as constituting the element scale; variations in accumulated volume over that area are assumed to be of no significance, only the total volume for the element area. For densely planted field crops, that area is commonly thought of as a point. The distribution, ultimately, is expressed over all the elemental areas containing plants in the field. It follows that if, say, vine spacing varies, or catch-can spacing for evaluating sprinkler overlap varies, or advance and recession times 
are evaluated for points spaced nonuniformly in a border, then the distribution from which to calculate $D U$ consists of volume per unit area for each element, weighted by that element's fraction of total area. In this approach the elements must be so chosen that all of the water applied is accounted for.

The concept of element scale is crucial in the universal definition of $D U$. In orchards and vineyards, a $D U_{l q}$ of 1.0 would not imply that every portion of the field received the same amount of water, but only that equal element areas received equal amounts of water (note the tacit implication that $D U$ is independent of variations in element or plant size). In a wheat field, on the other hand, with a plant virtually at every point, uniform coverage of all points is important, and a $D U_{L q}=1.0$ would indeed imply that each point in the field received the same amount of water (point still implies an elemental area).

$D U$ is usually defined as the ratio of some measure of the smallest accumulated depths in the distribution, to the average depth accumulated. In principle, a uniformity ratio could be defined equally well in terms of a measure of the largest values in the distribution. Without a sense of the actual variation in applied depth over the field area, no single numerical value describes that variation completely. With some assumptions about the actual shape of the accumulated water distribution function, one definition is as good as another. Still, because of the importance of adequate irrigation to crop production, the smallest depths have traditionally been chosen to express uniformity.

An appreciation of the smallest depths in the distribution is afforded by averaging the smallest depths in that portion of the field containing them. This average $d_{\text {lowest }}$ is then used in the numerator of the $D U$ definition, rather than using the absolute minimum value. The numerical value of $D U$ so obtained clearly depends on the fraction of the total field area chosen to define average $d_{\text {lowest }}$, and thus, the symbol $D U$ must be augmented with a subscript defining that fraction (i.e., $D U_{a}$ ). In some theoretical studies, the absolute minimum value in the distribution (aforementioned fraction of area $a=0.0$ ) has been used, but for field use, this is often impractical. In general, the fraction chosen depends on the management objectives of the irrigation system. The lowest $1 / 4$ has been used by the USDA NRCS (formerly the SCS) since the 1940s. It has proven to be practical and useful in irrigated agriculture and leads to the definition of average low-quarter depth, $d_{l q}$, the average of the depths accumulated in that quarter of the field area receiving the smallest depths (ASCE 1978), that is,

$d_{l q}=\frac{\text { vol. accum. in } 1 / 4 \text { total area of elements w/smallest depths }}{1 / 4 \text { of the total area of elements }}$

Then, the low-quarter distribution uniformity, $D U_{l q}$, is defined

$$
\begin{gathered}
D U_{l q}=\frac{d_{l q}}{d_{\text {avg }}} \\
D U_{l q}=\frac{\text { avg. low-quarter depth }}{\text { avg. depth of water accumulated in all elements }}
\end{gathered}
$$

where $d_{\text {avg }}=$ total volume accumulated in all elements, divided by total area of all elements. These definitions allow elements to be of different size (i.e., by properly weighting areas).

$D U_{l q}$ was developed by the USDA-NRCS and has been widely accepted by others (e.g., Burt et al. 1992) because

1. Rather than incorporating the absolute minimum value (which would be 0 , if in the case of a vineyard irrigation system with a single emitter per vine, one was plugged), it uses a definable element, which is easy to show to farmers.
2. The quarter of the field, with approximately $1 / 8$ underirrigated (exactly $1 / 8$ with a linearly varying distribution of values), seems to be both practical and economical for management, for example, related to observation of water stress and crop growth.

$D U$ is not an efficiency term. To underscore this, it is recommended that $D U$ be presented as a ratio, not a percent. An irrigation may be very uniform (have a high $D U$ ), but if the water applied is excessive, there may be unnecessary runoff and deep percolation, with a resulting low application efficiency ( $A E$, defined in the next section). However, a high $A E$ with minimal underirrigation can only be achieved if the $D U$ is also high. Therefore, conducting a field evaluation of the $D U$ of an irrigation system is often one of the very first steps in evaluating and improving on-farm irrigation efficiency.

Fig. 12 shows typical uniformity subpatterns of some components of furrow, sprinkler, and drip/micro systems. It can be noted that, for a single furrow on a uniform soil, most of the furrow length receives a relatively large depth of water, with a small fraction receiving a relatively small depth. The concept of $d_{l q}$ was developed at a time when surface irrigation methods dominated irrigation. Since the major variations occurred at the "low end" of the values, the "low quarter" concept was emphasized. It still has considerable merit when one considers
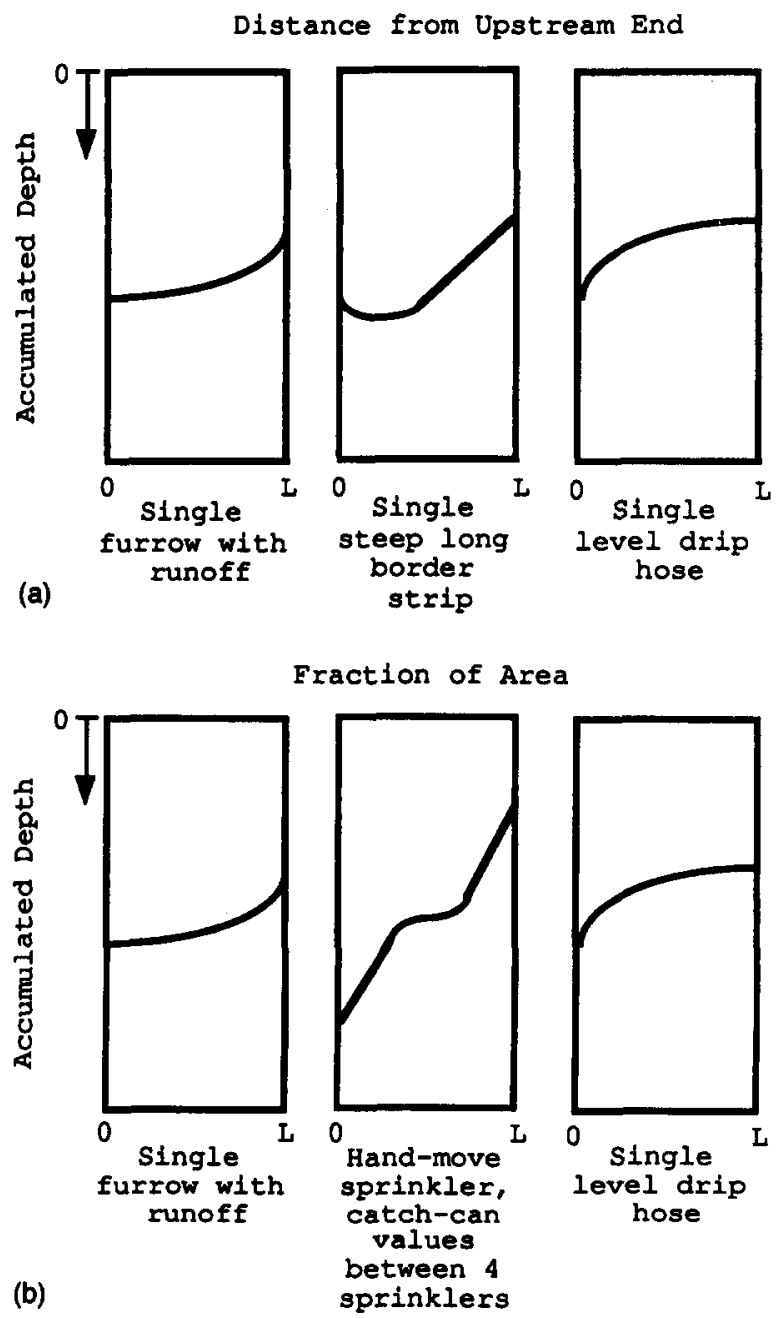

FIG. 12. Typical Variations in Accumulatod Water with Location and Arranged by Magnitude: (a) Typical Variation In Local Accumulation of water; Furrow and Border Strip Variations due to Opportunity-Time Differences Only; Drip Variation due to Pressure Variation Only; (b) Typical Varlation in Water Accumulated; Values Are Arranged by Magnitude, Rather Than by Location 
irrigation scheduling and the concept of adequacy for any irrigation method. Adequacy is defined later in this section.

However, there are times when one must consider the high end of the distribution. For example, when one examines the uniformity of flow rates along a single drip/microirrigation hose with noncompensating emitters on flat ground (ignoring manufacturing variation and plugging), it is apparent that the distribution is somewhat reversed from a single furrow (see Fig. 12). Most of the variation occurs with the small percentage of emitters having high flow rates. For cases where a crop is sensitive to overwatering (e.g., tomatoes or peppers on heavy clay soils with aeration problems), performance measures that consider the high end of the distribution can be useful. Ratios such as maximum/average or maximum/minimum have been used to indicate potential yield problems. However, the high end of the distribution can be treated just like the low end - for example, average of high quarter (or fraction of area) divided by the average over the total area.

New irrigation methods currently under development intend to supply a nonuniform amount of water based on variable needs (a part of precision or prescription farming). For this type of system, a new definition of $D U$ will be required to take into account a nonuniform target. Such definitions should be based on the relationship between the actual and target depths for each element area. This relationship can be based either on differences or on ratios, with the former being somewhat easier to handle statistically.

\section{Application Efficiency, $A E$}

The irrigation efficiency, irrigation sagacity, and irrigation consumptive use coefficient terms are, in principal, difficult to evaluate rapidly and require a detailed inventory and quantification of the ultimate (not projected or anticipated) destinations and uses of irrigation water that was applied at some earlier date. Yet it is necessary at times to plan for the future, and it is often necessary to judge the performance of an irrigation system in the field, when the matter revolves not about the issue of what the plant needs in fact are, but about how well, or efficiently, the system satisfies a perceived need (e.g., target depth).

The matter is resolved through introduction of another efficiency term, application efficiency, $A E$, which is based on the concept of meeting a target irrigation depth for that event. This separates the issues of establishing the beneficial or prudent value for the target depth from the issue of how well the irrigation system meets a given target depth. $A E$ is used to estimate what happens during a single irrigation event, even though the water has not yet been used, for example, for $E T$. The chosen target depth may be the soil moisture (water) depletion, $S M D$, or some smaller amount to accommodate potential rainfall. The target depth may contain a desired depth of reclamation water, or it may contain a maintenance leaching fraction as well as the $S M D$. In any event

$$
A E=\frac{\text { avg. depth of irrig. water contributing to target }}{\text { avg. depth of irrig. water applied }} \times 100 \%
$$

This updated definition departs from the previous $A E$ definition (ASCE 1978) in that the previous definition only considered $S M D$ and did not include any water for leaching or other perceived beneficial uses. For this special case

$$
A E_{(S M D)}=\frac{\text { avg. depth of water contributing to the } S M D}{\text { avg. depth of irrig. water applied }} \times 100 \%
$$

In contrast to the definitions of irrigation efficiency and irrigation sagacity, in which it is understood that the beneficial uses are not necessarily uniformly discributed over a field, implicit in this definition of application efficiency is the assumption that the target depth is uniform over the subject area (or that special management such as precision irrigation is available to match known, nonuniform targets). Furthermore, a stated requirement eliminates the necessity for specifying a time period in the definition. With application efficiency referring to a single event with an identified target depth, rather than to a period of time over which benefits are realized, changes in soil water storage (which are implied in the numerator) do not explicitly appear in the definition.

If the requirement is just equal to the sum of the expected beneficial uses, application efficiency $(A E)$ provides an estimate for the potential irrigation efficiency (i.e., what the $I E$ will be if the expected benefits occur, and if the beneficial uses are uniform over the field). $A E$ will typically be higher than $I E$ since there is often unavoidable, nonbeneficial evaporation (e.g., sprinkler droplet drift). Furthermore, water applied with a high $A E$ may not be beneficially used if the timing is poor (e.g., at the end of the growing season when crop ET drops to 0 ).

The On-Farm Committee (ASCE 1978) presented the concept of low-quarter application efficiency $\left(A E_{k q}\right)$ to account for irrigation water that is stored within the root zone after an irrigation event; but that may not be useful in the future because of irrigation nonuniformity. $A E_{l q}$ uses the low-quarter depth divided by the average depth applied as the measure of irrigation performance. The rationale for this is that if irrigations are scheduled to avoid crop-water stress in the low-quarter area of the field, and it is assumed that the distribution of water from successive irrigations is similar, then the areas that received more than the low-quarter depth in the previous irrigation will not be able to utilize that water before receiving more. In this case we suggest that $A E$ be used, rather than $A E_{l q}$, and that the requirement be changed to the low-quarter depth. On the other hand, if the plants in the low quarter are significantly stressed between irrigations, whether by accident or by intentional deficit irrigation, then this adjustment is not appropriate, and no adjustment or one based on some larger field area may be appropriate. The significance of $A E_{l q}$ is somewhat uncertain for a given irrigation, since it depends on the intent of the irrigation and on future scheduling.

\section{Potential Application Efficiency, PAE, PAE}

The concept of potential application efficiency, PAE, is also useful in measuring the performance of a system for a single irrigation event. PAE is based on the concept that the application could be terminated at such time that the target would be just met by the average of the lowest values in the irrigation infiltration distribution. Deep percolation losses would then be held to a minimum, and the application efficiency would be at a maximum without significant underirrigation. Deep percolation would be minimized, and due only to nonuniformity of the distribution.

$P A E$ is thus a reasonable criterion for computing a water order to satisfy a given requirement, provided the average of the lowest values is satisfactory from an agronomic standpoint. A small fraction of the field remains underirrigated, but the requirement is essentially satisfied in the field. Hence, the characterization "potential" is assigned to the application efficiency. As in the case of $D U$, this concept cannot be quantified until the lowest values in the distribution have been characterized by a specified fraction of field area. Again, as in the case of $D U$, current practice supports the value 1/4. As noted earlier, if the variation of infiltrated depth with field area were linear, this would imply that $1 / 8$ of the field remains (slightly) underirrigated. Thus, the potential application efficiency of the low quarter, $P A E_{l q}$, for a single event is defined 
$P A E_{l q}=\frac{\text { avg. depth of irrig. water contributing to target }}{\text { avg. depth of irrig. water appl. such that } d_{l q}=\text { target }}$

$\times 100 \%$

Using $P A E_{l q}$ one can determine the gross amount of water to apply; note that the denominators of $D U_{l q}$ and $P A E_{l q}$ differ, in essence, by the amount of surface losses (uncollected runoff and evaporation during the irrigation). For irrigation scheduling purposes, with a target depth at the average low-quarter value, $P A E_{l q}$ can be estimated in advance, if the surface losses are accurately estimated (the estimate is usually a little high), as

$$
P A E_{l q} \approx D U_{l q} \times(100-\% \text { surface losses })
$$

where surface losses are composed of evaporation during the irrigation, spray drift, and uncollected surface runoff. This approximation is usually better for pressurized irrigation systems, where $D U_{l q}$ and \% surface losses do not change as much with application depth as they do for surface irrigation systems, where they can change dramatically.

It follows that the gross irrigation water required for an irrigation event with proper irrigation scheduling can be estimated as

$$
\text { Gross average depth to apply } \approx \text { Target depth } \times \frac{100}{P A E_{l q}}
$$

\section{Low-Quarter Adequacy, $A D_{19}$}

It is possible to attain a very high $A E$ in a field by underirrigating. A parameter, complementary to $A E$, indicating the degree to which the target or required depth is met should be included in any list of pertinent performance measures. In keeping with the aforementioned definition for $A E$ based on a requirement stemming from all proposed beneficial uses, the low-quarter adequacy of an irrigation, $A D_{l q}$, is defined as follows:

$$
A D_{l q}=\frac{d_{l q}}{d_{r e q}}
$$

If the average low-quarter depth, $d_{l q}$, is used as the scheduling criterion, then a "proper" irrigation duration will result when $A D_{l q}=1.0$, with about $1 / 8$ of the field underirrigated (adoption of the criterion $A D_{l q}=1.0$ targets the average low-quarter depth $d_{i q}$ rather than the absolute minimum depth). With this definition, $A D_{l q}<1.0$ implies underirrigation, whereas $A D_{l q}>1.0$ implies overirrigation, as shown in Table 2. This is in contrast to other definitions of adequacy that are based on the percentage of the area adequately irrigated, varying from 0 to $100 \%$.

\section{Statistical Expressions of Uniformity, $C V, S D U$}

An alternate approach to expressing uniformity is based on a statistical analysis of the depths in the distribution. The coefficient of variation, $C V$, is such a statistical measure of irrigation uniformity

$$
C V=\frac{\text { Std. dev. of accum. water depths (weighted by area) }}{\text { Mean water depth }}
$$

The type of statistical distribution (i.e., its shape) determines the relationship among a statistic, such as $C V$, and other uniformity parameters, say $D U_{l q}$. Distribution uniformity, $D U$, can be estimated from these standard statistics if the nature of the distribution is known or estimated. Indeed

$$
S D U_{a}=1-K_{a} \times C V
$$

TABLE 2. Interpretation of Various $A D_{k q}$ Values

\begin{tabular}{c|l}
\hline \hline $\begin{array}{c}\text { Characterization of } \\
\text { the irrigation } \\
(1)\end{array}$ & \multicolumn{1}{|c}{$\begin{array}{c}\text { Values of } A D_{l q} \\
\text { (2) }\end{array}$} \\
\hline Underirrigation & $\begin{array}{l}A D_{l q}<1.0 \\
\text { Difference from } 1.0 \text { reflects degree of } \\
\text { underirrigation } \\
A D_{l q}=1.0 ; A E=P A E_{l q} \\
\text { Surface losses match potential values. } \\
A D_{l q}>1.0 \quad \text { from } 1.0 \text { reflects degree of } \\
\text { Difference from } \\
\text { overirrigation. }\end{array}$ \\
\hline
\end{tabular}

where $S D U=$ statistically derived estimate of $D U$; subscript $a$ $=$ fraction of area having lowest depths in distribution; and $K_{a}$ $=\mathrm{a}$ parameter related to both distribution type and area fraction. For evaluation purposes it is assumed that $D U \approx S D U$. For $a=$ low quarter of the area, and a normal distribution of values, it has been shown (Hart 1961; Hart and Reynolds 1965 ) that $K_{l q}=1.27$, which gives the well-known relationship

$$
S D U_{l q}=1-1.27 \times C V
$$

For the low half of the values in a normal distribution, Hart and Reynolds (1965) showed that $K_{t h}=0.798$, leading to the result

$$
S D U_{k h}=1-0.798 \times C V
$$

For $D U$ based on the greatest depths in the distribution, rather than the lowest depths, the minus sign in (13)-(15) becomes a plus. Otherwise, the statistical procedures are identical to those for $D U$ based on the low area. The variation in $D U_{a}$ as a function of the low fraction of area, $a$, is shown in Fig. 13, which was constructed from a normal distribution of depths.

Worthy of note, for a normal (or other symmetrical) distribution, $D U_{l h}=U C$, the Christiansen uniformity coefficient (Christiansen 1942) was developed to describe the uniformity of sprinkler overlap. The Christiansen uniformity coefficient, $U C$, is based on the average of absolute deviations from the mean and was developed before the use of hand-held calculators and the development of agricultural statistics. The $U C$ assigns a higher uniformity value to an irrigation distribution than the $D U_{l q}$, and is still used in the sprinkler industry to describe sprinkler overlap uniformity.

As noted in the foregoing, the fraction of total area bearing the lowest values in the distribution influences the numerical value of $D U$, as does the shape of the distribution. Examples

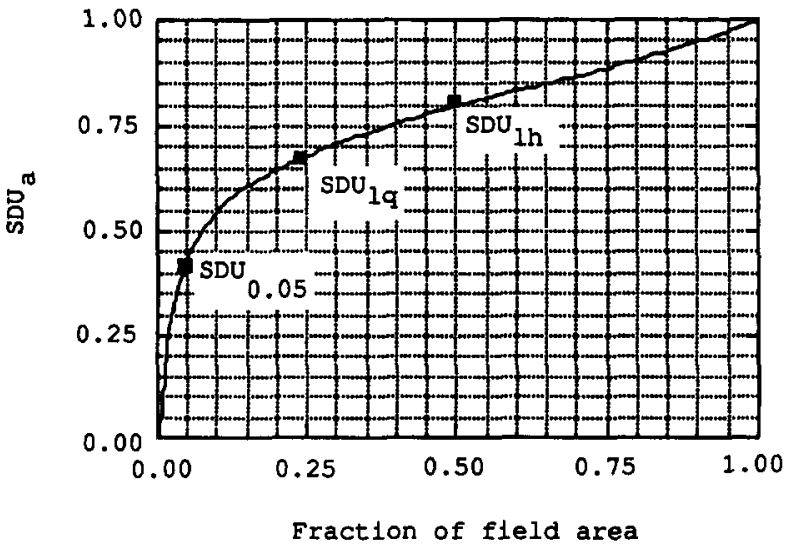

FIG. 13. Relationship between SDU, and Defining Fraction of Fleld Area Having Lowest Depths in Distrlbution (Values Normally Distributed with $C V=0.25$ ) 
of the relationship between the value of $D U$ and the fraction of field area used to define it, derived from a normally distributed set of accumulated depth values with $C V=0.25$, are shown in Fig. 13.

The progression of $S D U_{a}$ values with decreasing fractional area is noteworthy, with the old Christiansen $U C$ referring to half the total area, $D U_{l q}$ to the low quarter, and some irrigatedturf values referring to the low 5 or $10 \%$. With field measured distributions, the relationship is also relatively smooth throughout most of the range, though it can drop off sharply to zero at low values of area fraction. When uniformity is especially important in high value crops, it is worthwhile to consider using the smaller fractions of area to define uniformity.

\section{DU Components and Global Distribution Uniformity}

It has become customary, with the different irrigation methods, to focus uniformity studies on particular causes of nonuniformity in the ultimate distribution of accumulated water in the field. For example, in surface irrigation, the advance and recession curves for a single furrow have been studied, with an eye to making the opportunity times equal, over the length of run. Grids of catch cans have been used to study the distribution of precipitation from a single sprinkler, or the overlapping pattern from several neighboring sprinklers. A traditional concern in microirrigation has been the uniformity of emitters as manufactured-mass production of these devices does not yield precisely the same pressure/discharge characteristics for each.

From the standpoint of the crop, however, it is field-wide uniformity that is pertinent, that is, the degree to which the plants in the entire irrigated area are supplied equally with water. In surface irrigated fields, variations in soil-infiltration characteristics along the length of run, and also transversely, say, from furrow to furrow, influence the overall, or global uniformity, as do variations in inflow from furrow to furrow and varying surface elevations over the field (Clemmens 1986, 1991). Nonuniformity in distribution over a sprinkled field depends not only on distribution patterns from adjacent sprinklers but also on the pressure distribution in the system of laterals feeding the sprinklers, as well as on the variation in nozzle sizes throughout the field. Similarly, microirrigation uniformity also depends, in part, on the pressure pattern in the lines and emitter plugging.

In principle, there are many sources of nonuniformity, the contribution of each tending to reduce the global uniformity in the system. Examples of the components that affect uniformity with various irrigation systems are given in Table 3. While it is impractical to actually measure field-wide uniformity of distribution, it is feasible to study the uniformity of the individual components, including the aforementioned traditional ones. It is important, however, to study the effects of all the components, and to combine the results in such a way as to provide a good estimate of the global uniformity. The matter of combination is discussed further in a subsequent section and in companion papers. For the moment, suffice it to say, the only theoretically defensible combinations of component $D U \mathrm{~s}$, each reflecting some random variation, is through proper statistical procedures. This technique also has significant advantages in explaining the relative impact of various physical constraints and irrigation system components on the real, that is, global uniformity.

The lack of a statistical basis for the Christiansen $U C$, for example, precludes combining the results for sprinkler overlap, which traditionally the UC describes, with some description of uniformity of the pressure distribution in the laterals. For this and other reasons, $D U_{l q}$ is being adopted ever more widely, whereas the relative usage of $U C$ has declined. There- fore, except for occasional references, the $U C$ term is not used in this paper.

\section{QUANTIFYING IRRIGATION WATER SOURCES AND DESTINATIONS, AND ASSOCIATED PERFORMANCE INDICATORS (IE, IS, ICUC)}

The numerical values of irrigation performance measures $(I E, I S, I C U C)$ provide convenient terms to express the overall effectiveness of the irrigation system and its management. However, such indicators rely on our ability to quantify the various water sources and destinations. There can be several methods for determining the volume associated with each water use. Each method has errors associated with it, so the most appropriate method to use usually depends on site-specific conditions. It is not the intent here to recommend one method over another, but simply to point out some of the limitations that make quantifying these water uses difficult.

The results of quantification of water sources and destinations must satisfy a water balance. This is complicated by rainfall and by surface and subsurface flow into and out of the region of interest. For many systems, it is difficult, if not impossible, to accurately separate water that reaches a given destination into irrigation and rainfall-runoff components. In general, it is usually considered that if irrigation occurs after a rainfall event, then the rainfall is effectively used, and any irrigation water in excess of the reduced need is not beneficially used. Conversely, if rainfall follows an irrigation, the rainfall is considered ineffective. However, if the rainfall was predictable and more or less certain, as in some relatively humid climates, one could argue that the irrigation was unnecessary and therefore not beneficial. No attempt is made to resolve these issues of judgment here.

\section{Defining Boundaries}

Proper quantification of water uses requires careful definition of boundaries, both laterally and vertically. Lateral boundaries depend on the geographic region under consideration. However, at times it is necessary to include areas not part of the region of interest or not farmed, so that flows into and out of the defined region can be more easily quantified. Vertical boundaries are much more difficult to define. For an individual field, the bottom of the root zone is commonly taken as the lower vertical boundary. It is difficult to measure vertical flow below the root zone, and in many cases this is taken as the only unknown or remainder in the water balance. With shallow water tables, this is not an appropriate boundary, since neither deep percolation nor ground water uptake can be easily estimated. However, including shallow ground water in the water balance is also problematic, unless ground water flow into and out of the system can be defined. Finally, for large hydrologic basins (with one or more irrigation organizations or projects) with restricted inflows and outflows, the lower boundary can include the entire ground water basin. The definition of boundaries has a significant influence on both the quantities that must be measured and the accuracy to which water-use estimates can be obtained.

\section{Quantifying Water Supplies}

Water sources for irrigation are often not accurately known. Some typical problems are

- Inaccurate or no water measurement device at source of supply

- No continuous recording of flows that vary with time

- Undocumented or poorly documented splitting of flows in irrigation canals 
TABLE 3. Examples of Components that Affect Uniformity whth Various Irrigation Systems

\begin{tabular}{|c|c|}
$\begin{array}{c}\text { Uniformity component } \\
\text { (1) }\end{array}$ & Factors causing nonuniformity \\
\hline
\end{tabular}

(a) Components and factors of $D U$ for hand-move sprinkler irrigation systems

\begin{tabular}{|c|c|}
\hline $\begin{array}{l}\text { Flow rate differences between } \\
\text { sprinklers }\end{array}$ & $\begin{array}{l}\text { Pressure differences } \\
\text { Different nozzle sizes } \\
\text { Nozzle wear } \\
\text { Nozzle plugging }\end{array}$ \\
\hline $\begin{array}{l}\text { Sprinkler pattern (catch can) } \\
\text { nonuniformity }\end{array}$ & $\begin{array}{l}\text { Spacing } \\
\text { Sprinkler design (angle of trajectory, } \\
\text { characteristics of impact-arm inter- } \\
\text { ception) } \\
\text { Nozzle size and pressure } \\
\text { Wind } \\
\text { Vertical orientation of sprinkler head } \\
\text { Plant interference around the sprinkler }\end{array}$ \\
\hline $\begin{array}{l}\text { Unequal application during } \\
\text { start-up and shutdown } \\
\text { Edge effects }\end{array}$ & $\begin{array}{l}\text { Pipe diameter and length } \\
\text { Duration of set } \\
\text { Inadequate overlap on field edges }\end{array}$ \\
\hline
\end{tabular}

(b) Components and factors of $D U$ for furrow irrigation systems

\begin{tabular}{|c|c|}
\hline $\begin{array}{l}\text { Opportunity-time differences } \\
\text { down a furrow }\end{array}$ & $\begin{array}{l}\text { Extent of ponding } \\
\text { Flow rate and duration } \\
\text { Slope } \\
\text { Roughness } \\
\text { Furrow cross section } \\
\text { Furrow length }\end{array}$ \\
\hline $\begin{array}{l}\text { Opportunity-time differences } \\
\text { between furrows }\end{array}$ & $\begin{array}{l}\text { Different day/night set times } \\
\text { Wheel row/nonwheel row differences } \\
\text { Different furrow flow rates }\end{array}$ \\
\hline $\begin{array}{l}\text { Different infiltration character- } \\
\text { istics for individual furrows }\end{array}$ & $\begin{array}{l}\text { Different degrees of compaction due to } \\
\text { tillage and tractor tires }\end{array}$ \\
\hline $\begin{array}{l}\text { Different infiltration character- } \\
\text { istics across the field }\end{array}$ & $\begin{array}{l}\text { Soil differences } \\
\text { Chemical differences } \\
\text { Texture differences }\end{array}$ \\
\hline $\begin{array}{l}\text { Other opportunity time differ- } \\
\text { ences throughout a field }\end{array}$ & Nonuniform land grading \\
\hline $\begin{array}{l}\text { Differences in day and night in- } \\
\text { take rates }\end{array}$ & $\begin{array}{l}\text { Viscosity changes due to temperature } \\
\text { differences }\end{array}$ \\
\hline $\begin{array}{l}\text { Infiltration rate differences due } \\
\text { to differences in wetted pe- } \\
\text { rimeter }\end{array}$ & $\begin{array}{l}\text { Slope changes or flow restrictions along } \\
\text { the furrow }\end{array}$ \\
\hline
\end{tabular}

(c) Components and Factors of $D U$ for drip/microirrigation systems

Differences in discharge between emitters

\begin{tabular}{l|l} 
Volumes applied not propor- & $\begin{array}{l}\text { Plagging of emitters } \\
\text { Manufacturing variation } \\
\text { Soil differences, if the emitters are bur- } \\
\text { ied } \\
\text { Different emitter types in the same field } \\
\text { Temperature differences along a lateral } \\
\text { Variations in plant spacing are not } \\
\text { ing same plant age) }\end{array}$ \\
$\begin{array}{l}\text { matched by emitter spacing or sched- } \\
\text { uling } \\
\text { Unequal discharge during start-up and } \\
\text { drainage }\end{array}$ \\
\hline
\end{tabular}

(d) Components and factors of $D U$ for center pivots and linear-move sprinkler irrigation systems

\begin{tabular}{c|l}
\hline $\begin{array}{c}\text { Sprinkler/spray head flow rates } \\
\text { not proportional to area } \\
\text { served }\end{array}$ & $\begin{array}{l}\text { Poorly controlled sprinkler pressures } \\
\text { Elevation changes } \\
\text { Pressure regulator differences } \\
\text { Nozzle plugging } \\
\text { Nozzle wear }\end{array}$ \\
$\begin{array}{l}\text { Sprinkler overlap nonuniform- } \\
\text { ity between adjacent sprin- } \\
\text { klers }\end{array}$ & $\begin{array}{l}\text { System travel speed variations } \\
\text { Sprinkler/spray head elevation } \\
\text { Crop interference } \\
\text { Worn spray plates } \\
\text { Spacing } \\
\text { Wind direction changes } \\
\text { Soil texture } \\
\text { Distance from pivot } \\
\text { Surface conditions (dikes, residues) } \\
\text { Angle changes from topography }\end{array}$ \\
\hline
\end{tabular}

TABLE 3. (Continued)

\begin{tabular}{c|l}
\hline \multicolumn{1}{c|}{$(1)$} & \multicolumn{1}{c}{ (2) } \\
\hline Radial arc effects & $\begin{array}{l}\text { Activation of end guns and corner swing } \\
\text { lateral sections or towers without proper } \\
\text { control of rates along pivot } \\
\text { Engine performance } \\
\text { Pump response to different pressure re- } \\
\text { quirements } \\
\text { Source pressure variations }\end{array}$ \\
\hline
\end{tabular}

(e) Components and factors of $D U$ for under-tree sprinkler irrigation systems

\begin{tabular}{|c|c|}
\hline $\begin{array}{l}\text { Same as hand-move sprinklers, } \\
\text { except sprinkler overlap non- } \\
\text { uniformity around each } \\
\text { sprinkler is typically not } \\
\text { considered, if there is one } \\
\text { sprinkler for every two trees }\end{array}$ & $\begin{array}{l}\text { Tree interference can cause large, non- } \\
\text { irrigated areas or segments in some } \\
\text { cases. }\end{array}$ \\
\hline \multicolumn{2}{|c|}{$\begin{array}{l}(f) \text { Components and factors of } D U \text { for high-volume gun sprinkler } \\
\text { irrigation systems }\end{array}$} \\
\hline $\begin{array}{l}\text { Flow rate differences between } \\
\text { sprinkler locations }\end{array}$ & $\begin{array}{l}\text { Pressure differences } \\
\text { Length of supply pipeline } \\
\text { Hose on reel rather than on ground } \\
\text { Elevation differences }\end{array}$ \\
\hline $\begin{array}{l}\text { Sprinkler overlap nonuniform- } \\
\text { ity }\end{array}$ & $\begin{array}{l}\text { Plant interference around ground- } \\
\text { mounted sprinklers } \\
\text { Wind } \\
\text { Lane and/or sprinkler spacing, nozzle, } \\
\text { and pressure } \\
\text { Gun travel speed }\end{array}$ \\
\hline Edge effects & $\begin{array}{l}\text { Lane spacing } \\
\text { Wind driven changes } \\
\text { Wind velocity changes }\end{array}$ \\
\hline System flow variations & $\begin{array}{l}\text { Engine performance } \\
\text { Pump response to elevation changes } \\
\text { Source pressure variations }\end{array}$ \\
\hline $\begin{array}{l}\text { Speed variation with continu- } \\
\text { ously moving systems }\end{array}$ & $\begin{array}{l}\text { Wheel slippage } \\
\text { Water turbine power output fluctuation } \\
\text { Cable or hose depth on reel }\end{array}$ \\
\hline
\end{tabular}

- Poor record keeping

- Inadequate rainfall records

- Inaccurate separation of rainfall from irrigation water

\section{Quantifying Water Uses}

This section focuses on issues related to the main components in the water-use partition diagram (Fig. 10):

- $E T_{c}$ - a consumptive/beneficial use

- Deep percolation for salt removal-a nonconsumptive/ beneficial use

- Consumptive/nonbeneficial uses: sprinkler and weed $E T$

- Nonconsumptive/nonbeneficial uses: runoff and deep percolation in excess of leaching requirement

It is recognized that these are not the only components, but, generally, within the accuracy to which the performance measures can be estimated, they are the pertinent ones.

$E T_{c}$

$E T_{c}$ estimates can vary substantially among different effciency studies of the same region. Of course, there is only one actual $E T_{c}$. There are four main methods for estimating $E T_{c}$ :

1. Direct measurement of soil water depletion

2. Energy-balance calculations based on weather data and crop coefficients

3. Measurement of crop yield coupled to relationships between yield and $E T_{c}$ 
4. Water-balance approach, in which total ET is the remainder after all other components have been measured or estimated

Estimates of $E T_{c}$ are crucial for $I E$ estimates, so the following discussion is provided to point out the variety of problems that can make such estimates inaccurate and to introduce caution into interpretation of various published $I E$ numbers.

By economic necessity, $E T_{c}$ estimation from soil water depletion is typically based on measurements throughout the growing season at only a few "representative" sites within a field. The $E T_{c}$ values for those sites are then extrapolated for the whole field. Typical problems are the following:

- The data sets for the "representative"' sites may not agree with each other for unexplainable reasons.

- Soil water depletions in soils with high water tables do not indicate $E T_{c}$, because of the upward flux of water into the measurement zone. The existence of a high water table also makes soil water measurements meaningless, once the roots reach the capillary fringe. The contribution to $E T$ by the water table cannot be measured at the field scale.

- Nonuniform irrigation applications may cause deficits in some parts of the field not included in the "representative" sites.

- Parts of the field may have weak plant growth, resulting in low ET in those areas.

- During the soil water sampling, the site can be disturbed so that it is no longer representative; for example, trampling of vegetation around a neutron probe access tube, or channeling of water along a buried tube.

- The soil water measurement device may be incorrectly calibrated. It is difficult to have accurate calibrations for every $15 \mathrm{~cm}$ or so of soil depth on every site.

- If two woil water measurement techniques, say, a neutron probe and a time-domain reflectrometry device, are used on exactly the same site, different numbers can result.

- Most soil water measurement devices do not adequately measure soil water conditions near the soil surface, where there may be very large changes in moisture content. This is especially important for frequent, small irrigations.

- Estimates of changes in surface soil water content may be in error (e.g., it could be assumed that soil water content just before irrigation is at the wilting point, whereas, in fact, it is actually drier).

- The effective root-zone depth can be overestimated. Too often, the root-zone depth is assumed to be the average published depth. Less than normal rooting depths occur when plants are immature, overly frequent irrigation is practiced, or physical soil restrictions exist. Soil restrictions include increased soil density from the weight of heavy equipment, tillage pans, hardpans, and dry soil due to inadequate irrigation. If an overestimated root zone depth is used in a calculation of $E T_{c}$, the estimate may underpredict crop stress caused by limited soil water storage.

- The effective root-zone depth may be underestimated; for example, an estimate of a $1.5-\mathrm{m}$ root-zone depth for cotton, which ignores deep moisture withdrawal late in the season when the cotton is deliberately stressed prior to harvest.

- The timing of the soil water measurements may be such that slow drainage (deep percolation) is missed. Since field capacity is not a static concept, some "stored" water may eventually percolate down below the root zone. This is especially common on heavy-textured soils after preirrigations.

- There may be no "representative" spot to measure soil water depletions. This is the case for microirrigation, where only portions of the soil are wet, and plant wateruptake rates in various parts of the wetted root zone are quite different. Soil water measurements in fields with microirrigation systems can be valuable for indicating trends, but they are inadequate in defining $E T$ rates.

- The annual water balance may ignore the effect of "carryover" moisture from one growing season to another. For example, deep percolation beyond the root zone of a shallow-rooted plant, such as lettuce, may not be a loss if it remains in the potential root zone of a subsequent, more deeply rooted crop. This type of problem can be effectively eliminated by using the proper vertical boundary (for a field $I E$ study, this would be the greatest root-zone depth found in a crop rotation) and by quantifying the " $\Delta$ storage of irrigation water" component of the various equations.

$E T_{c}$ estimates based on crop coefficients and weather data are frequently used to estimate what the $E T$ "should have been," yet they can be very different from what actually occurred. Frequently, studies that use this approach do not provide any cross-check of the $E T_{c}$ estimates. The following are common sources of error:

1. The crop coefficients may be incorrect. A literature search targeting any crop will provide a range of crop coefficients, $K_{c}$

2. The crop coefficients assumed may have been developed for a different condition (e.g., crop coefficients based on days since planting do not take into account weather-related variations in crop maturity).

3. The crop coefficients may assume an evaporation component that is dependent on a different irrigation system and irrigation frequency.

4. Whenever water is used to achieve some special practice, there is the potential that it will impact the $K_{c} / E T_{c}$ relationship in ways not mirrored in the studies deriving $\boldsymbol{K}_{c}$.

5. The crop coefficient may assume a well-watered crop, whereas in reality the crop may be stressed.

6. The reference $E T$ estimate may be incorrect because of - Nonrepresentative weather station siting

- Instrument errors

- An insufficient number of weather stations available to represent a diverse geographical area

- Inaccurate equations to estimate reference $E T$

7. There may be errors in the estimates (or variations across a large area within the study boundary) of the planting, full canopy, and harvest dates. Crop growing season durations may be incorrect.

8. Crop acreage may be incorrectly measured.

9. ET may not be uniform across a field.

10. Effective precipitation may be difficult to estimate (only irrigation water $E T_{c}$ is used in the definitions for $I E, I S$, and $I C U C$ ).

There are a few crops for which the relationships between yield and $E T_{c}$ can be and have been established (this is not to be confused with relationships between yield and applied water, which are nontransferable to different conditions). For such crops $E T_{c}$ can be estimated from yield data; however, this requires extensive research. Error sources include the following:

- Inaccurate yield records

- Uncertainty in determining the potential yield in an area (since these relationships plot relative yield versus relative water use) 
- Nonunique relationships between $E T_{c}$ and yield, for example, because of differences in crop responses to water stress at different stages of growth or interactions with fertility, pest management, and disease control

- Variations among varieties of the same crop

- Effective precipitation uncertainty (see preceding)

- Variation in ET potential from year to year

Under certain geographic/geologic conditions, $E T_{c}$ based on a regional water balance may be an appropriate method for estimating the total $E T$ of the region. If all the flows into and out of a region are known, the difference is $E T$ or $\Delta$ storage. Other $E T$ components are subtracted from total $E T$ to arrive at $E T_{c}$. Error sources include the following:

- Inaccurate measurements of surface inflows and outflows.

- Inaccurate measurements of subsurface inflows and outflows.

- Difficulties in estimating the effective rainfall. For example, a judgment must be made whether the rain fell on irrigated or dry soil (i.e., was the deep percolation rainwater or irrigation water?) Also, it is difficult to estimate accurately the percentage of evaporation and runoff from rainfall.

- Estimates of evaporation from canals, reservoirs, and nonagricultural wet soil surfaces are difficult to obtain.

- Difficulties in estimating the net change in ground water storage.

- Phreatophyte ET is difficult to estimate.

Even with careful attention to detail, it is difficult to determine $E T_{c}$ on a field or larger scale, over a season, more accurately than $\pm 10 \%$ with any of the foregoing methods.

\section{Deep Percolation for Salt Removal}

Standard methods are available for estimating the amount of water that should be infiltrated over and above consumptive use to leach salts to maintain a desired average root-zone salinity. This amount, when described as a fraction of the required average irrigation application depth, is referred to as the leaching requirement, $L R$. This fraction, when converted to a depth, is that portion of the beneficial deep percolation, $d_{r b d p}$, required for maintaining soil salinity at an acceptable level (i.e., for soil maintenance). Estimates for $L R$ are usually based on acceptable values of the electrical conductivity of the soil water extract, $E C_{e}$. Another component of $d_{r b d p}$ is leaching water needed for soil reclamation. There are uncertainties associated with the theoretical methods for quantifying the leaching requirement, $d_{r b d p}$, for both reclamation and maintenance, and there is further uncertainty in determining what portion of the deep percolation water component has actually provided beneficial leaching of the soil. Error sources include the following:

- Uncertainty in threshold $E C_{e}$ values

- Possible extreme-temperature effects on $E C_{e}$

- Differences in salt tolerance among plant varieties

- Influence of soil water depletion on $E C_{e}$

- Influence of salt precipitation or dissolution on $E C_{e}$

- Influence of nonuniform infiltration

- Influence of preferential flow

- Influence of deep percolation frequency and timing

- Influence of soil salinity on $E T_{c}$, which changes the leaching volume required

- Uncertainty regarding the amount of water required to remove total salinity versus that required to remove specific toxic ions such as boron, under various water management scenarios
- Uncertainty regarding proper management of salt for rotation of crops with different salinity tolerance

Even when sufficient deep percolation for salt removal exists at a location in a field on average, because of soil nonuniformity, leaching may not occur over the entire soil volume at that location. Leaching effectiveness (ratio of volume of deep percolation water actually needed to lower average soil $E C_{e}$ to the desired value, relative to the required volume based on uniform deep percolation at each location) is dependent on the soil characteristics and the degree of soil saturation (Keren and Miyamoto 1990). Therefore, associated nonbeneficial deep percolation is, to some degree, reasonable. For a typical irrigation system, irrigation nonuniformity may provide adequate leaching over a large portion of the field even if the driest spot in the field has no leaching (Fig. 5). When leaching effectiveness is combined with irrigation nonuniformity, a significantly larger amount of water is needed to provide adequate leaching than that defined by $d_{\text {rbdp }}$ (see the deep percolation in the water destination diagrams of Figs. 14-16).

Salt removal is almost always accomplished through leaching. However, some amount of beneficial removal of salts via tailwater runoff has been documented in the heavy clay soils in the Imperial Valley of California (Rhoades et al., in press, 1996). This may reduce the actual leaching requirement.

\section{Consumptive/Nonbeneficial Uses}

It cannot be assumed that all water consumed is beneficial, yet separating beneficial $E T$ from nonbeneficial is often difficult. One must know if irrigations are excessively frequent and be able to estimate evaporation outside of the cropped field boundaries. As another example, catch-can recovery is often used to estimate aerial evaporative and spray losses from sprinklers. Problems with this include the following:

- Canopy interception of water that is beneficial

- Replacement of $T$ with $E$ due to the change in relative humidity

- Evaporation from catch cans

\section{Nonconsumptive/Nonbeneficial Uses}

Determination of runoff and nonbeneficial deep percolation is typically needed only to provide closure for a water balance. Numerous problems exist in measuring such quantities accurately due to the diffuse nature of hydrologic systems and the lack of economic incentives to routinely make such measurements (e.g., tailwater runoff).

\section{Uncertainty and Confidence Intervals}

Every measurement of a continuous variable, such as water volume (as opposed to discrete quantities that can be counted), contains an element of uncertainty, regardless of the variable and the method of measurement. This applies to all methods for estimating the water sources and destinations in the waterbalance diagrams. Confidence intervals are a standard statistical approach for describing the uncertainty associated with the estimate of each water quantity. The $95 \%$ confidence interval is commonly used and is recommended here. It represents the range within which we are $95 \%$ certain that the true value lies. For example, if the measured value is 10 , and the $95 \%$ confidence interval is $9-11$, then we are $95 \%$ certain that the true value lies between 9 and 11 .

For a normal distribution of measurements, the $95 \%$ confidence interval represents approximately 2 standard deviations. In practice, it may be convenient to simply set the confidence interval at \pm 2 standard deviations, which, as noted, is a $95 \%$ 
confidence interval for a normal distribution. For other types of distributions, \pm 2 standard deviations will not correspond exactly to the $95 \%$ confidence interval.

Errors in measurements include errors in the device calibration, in reading, in installation or zeroing, and so forth, and can be either systematic or random. Random errors are typically normally distributed. Repeated measurements at a given site can reduce the impact of random errors, since for a very large sample these random errors approach zero, but they do not remove systematic errors. Systematic errors, for example, from installation, are constant for one installation, but may vary randomly from installation to installation. Such errors are unknown for any given installation, but when considering the combined influence of many sites, they are often treated as random errors, again normally distributed. However, the average value for measurements at many similar sites may still contain a systematic error.

For many quantities of interest, more than one measurement is needed to determine a numerical value; for example, a quantity of interest may be constituted of two other quantities, added, subtracted, multiplied, or divided. Standard statistical equations are given in an accompanying paper (A. J. Clemmens and K. H. Solomon, unpublished, 1997) for determining the uncertainty of the result, given the uncertainty of the individual measurements. It is recommended that, where possible, confidence intervals be estimated for irrigation performance measures. For typical irrigation field studies, these confidence intervals may be fairly wide. The statistical equations given in Clemmens and Solomon (unpublished, 1997) can be used to determine which quantities contribute most to the uncertainty of the performance measure and to guide efforts to reduce uncertainty.

\section{QUANTIFYING EFFICIENCY FOR INDIVIDUAL IRRIGATION EVENT (AE, $A D_{1 q}$ )}

An irrigation evaluation may be conducted on any defined area of interest for any defined period. Different measurements will be taken if the area is an irrigation project, as opposed to a single field, or a single irrigation event versus a season. Evaluation of a single irrigation event on a single field (or single irrigation set) typically estimates $D U_{l q}$ and $A E$ (and associated $P A E_{l q}$ and $A D_{l q}$ ). Quick irrigation evaluations of a farm or field may not provide precise values for $D U_{l q}$ and $A E$, but they can still be valuable in defining the irrigation processes on a field or farm (i.e., for the purposes of improving overall irrigation system performance).

The on-farm application efficiency for a single irrigation event (i.e., on a specific date) will not necessarily be indicative of the overall seasonal or annual irrigation efficiency. For example, in many situations farmers may underirrigate during the summer, because of low infiltration rates and/or underdesigned irrigation systems. This deficit irrigation produces high $A E$ values if there is little deep percolation and if runoff is collected. Early season furrow irrigations, on the other hand, may have low $A E$ values, caused by a combination of high soil intake rates and low soil water depletions during that time

\section{Water Destination Diagrams}

Water-destination diagrams are often used to explain the concepts of $A E$ and $D U_{l q}$ (Burt 1983, 1989). Fig. 12 indicates typical patterns of water accumulation down a single lateral, furrow, or strip for some irrigation methods. The top row of graphs shows variation with location; in the bottom row, all values are arranged in order of magnitude, and, so, these diagrams do not indicate the location or cause of nonuniformity.

Figs. 14-16 show the amounts of water infiltrated throughout a field, rather than just down a single furrow, strip, lateral,

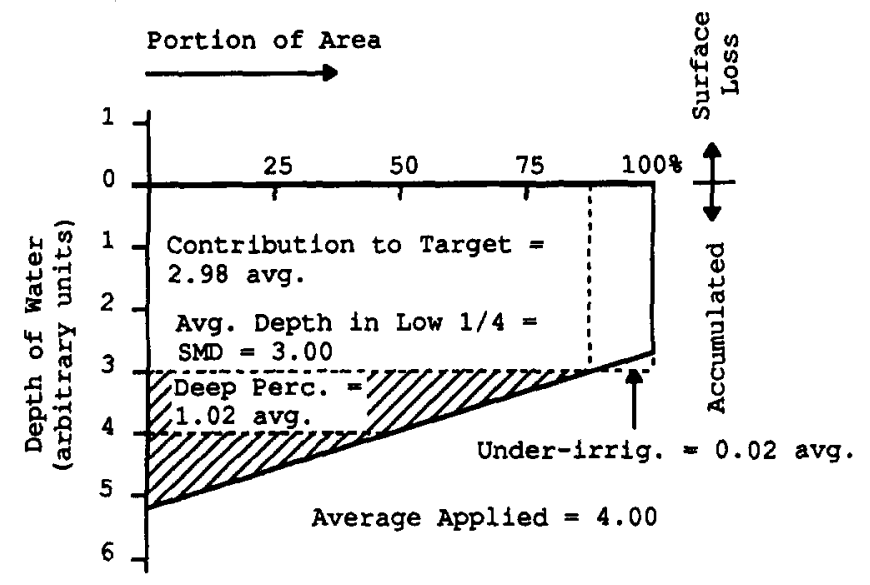

FIG. 14. Simplifled Case of "Perfect" Irrigation Scheduling: $D U_{1 q}=0.75 ;$ fleld $A E=74.5 \%$

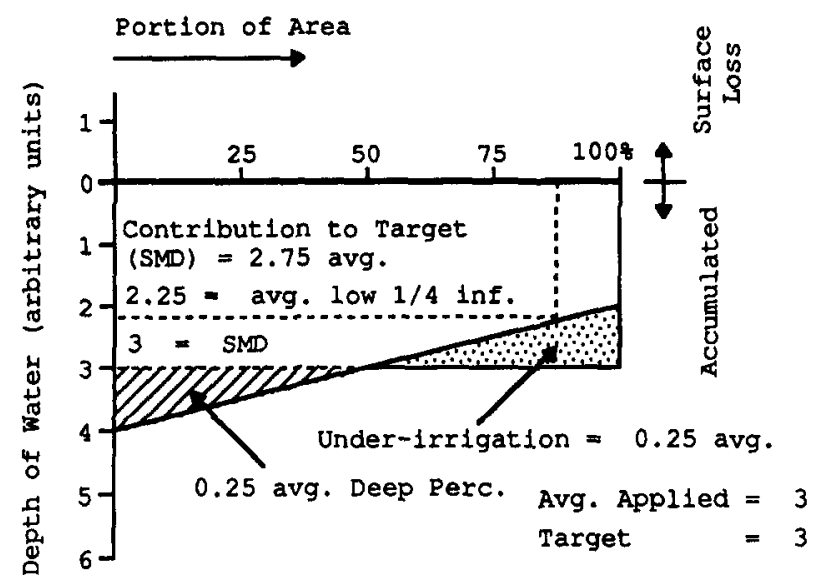

FIG. 15. Water Destination Diagram with Average Accumulated Depth Equal to Target Depth (3 Units) and No Surface Losses: $D U_{k q}=2.25 / 3=0.75 ; A D_{k q}=0.75$ (Underirrigation)

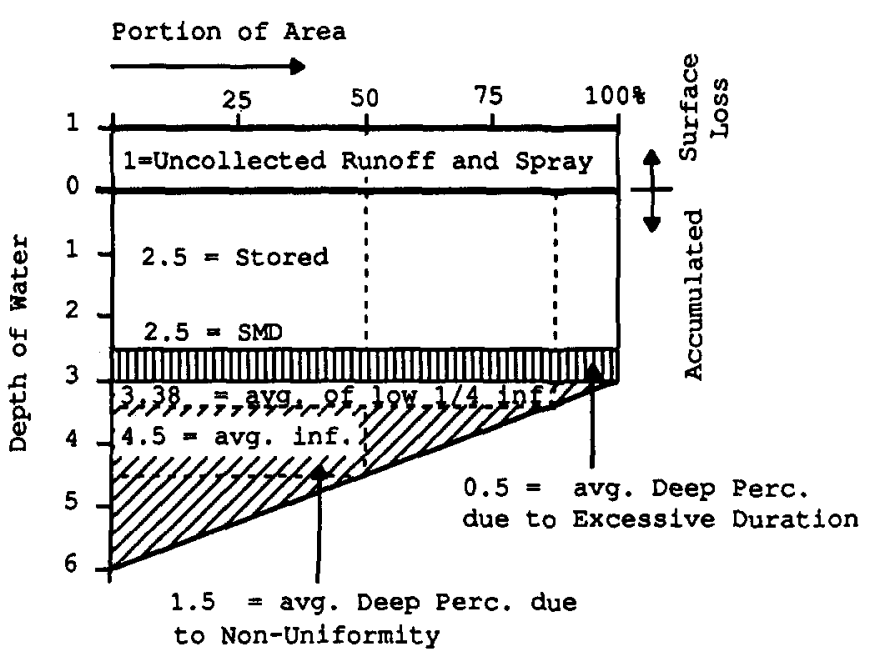

FIG. 16. Overirrigation on All of Fiold: $D U_{k q}=3.38 / 4.5=0.75$; $A E=2.5 / 5.5 \times 100=45.5 \% ; A D_{1 q}=3.38 / 3=1.13>1.0$ (Overirrigation)

and so on. It is assumed that all water accumulated is infiltrated. Runoff, evaporation, and spray losses are often shown as an equivalent uniform depth on the top of the diagram. These diagrams are applicable for all irrigation methods, although the causes of losses and nonuniformity are different for each irrigation method. Figs. 14-16 simplify the uniformity pattern by depicting it as linear, whereas the nonuniformity throughout the field may be closer to normal or some other 
statistical distribution. These figures are intended to serve as simplified illustrations of possibly difficult, interrelated concepts.

Fig. 14 indicates a case with a target depth of three units. All deep percolation is due to nonuniformity. This is an idealized case in which evaporation, spray, and runoff losses are negligible. Leaching needs are not considered in this sketch.

Fig. 15 indicates a case in which the target depth of three units is met "on the average," which results in underirrigation of half the field. This case assumes that no leaching is needed for salt control. With the initial target of three units, $A E=$ $(2.75 / 3) \times 100 \%=92 \%$; with target adjusted to low quarter, $A E=A E_{l q} \approx(2.25 / 3) \times 100 \%=75 \%$ [due to small deficit below low quarter, $A E_{l q}=(2.23 / 3) \times 100 \%=74.5 \%$ ].

Fig. 16 indicates a case in which the target depth of three units is exceeded at all points in the field. Deep percolation is caused by both nonuniformity and excess duration. Spray and runoff losses are significant. This case assumes that no leaching is needed for salt control.

Once the distribution of accumulated water is known, then $D U_{l q}$ and $A E$ (and possibly $P A E_{l q}$ ) can be readily determined. $D U_{l q}$ is known from the distribution itself, and $A E$ is based on fulfillment of a defined requirement. Determination of $I E$ is much more difficult and requires more precise knowledge of the real benefit from the irrigation, including the actual beneficial uses, rather than expected benefits from soil water storage and deep percolation-not an easy task.

Unfortunately, such diagrams of accumulated water, by custom, depict only the nonuniformity resulting from one or another cause and typically do not reflect the distribution of water resulting from all factors. Such distributions are more illustrative than accurate. As discussed in the following section, it is possible to estimate the $D U_{l q}$ from multiple effects without having to measure a complete water distribution (a task virtually impossible to perform on a field scale).

\section{QUANTIFYING UNIFORMITY (DU)}

\section{Factors Affecting $D U$}

The concept of distribution uniformity $(D U)$ applies to all irrigation methods. Values of $D U$, if measured completely and properly, should be comparable among various irrigation methods. That is, a $D U_{l q}$ of 0.80 on a sprinkler system should have implications regarding low application amounts similar to those of, say, a border strip system with a $D U_{l q}$ of 0.80 . A complicating factor with traditional evaluations is that reported $D U$ s are rarely global; that is, they have not taken into account all of the factors that influence uniformity across a field (Burt 1980).

The correct approach to evaluation of systems depends, in part, on the crop being irrigated. Worthy of note, the $D U$ cal- culated for microirrigation and sprinkler-irrigation systems on trees and vines does not account for nonuniform wetted patterns around the individual plants, even though a uniform wetted pattern may be important for various agronomic reasons. For example, catch-can uniformity is typically not even measured with under-tree sprinkler systems having one sprinkler per two trees, because it is assumed that, regardless of the overlap pattern, each tree will receive the same amount of water. This may be true once the trees are mature, as root systems adapt to the spatial pattern of water availability. However, a good sprinkler overlap pattern can be very important to ensure growth of young trees before the root systems have expanded.

Although the concept of $D U$ is the same for each method, the spatial distribution of the nonuniformity will be different for various irrigation methods. Table 4 indicates some possible locations of low application depths (or volumes) throughout fields with various irrigation methods.

The factors affecting $D U$ for each method are different. It may not be necessary to quantify the exact relationship between cause and effect for each factor in the nonuniformity, but the effects of each must be considered. Aboveground drip systems are the simplest to evaluate, because most of the nonuniformity can be directly measured, that is, by simply measuring the flow from individual emitters. Hand-move sprinklers are more difficult to evaluate, because in addition to flow rate differences at emission points, water is aerially distributed prior to arrival at individual plants. Center-pivot evaluations must weigh sprinkler-discharge measurements by the area served by each sprinkler. This applies also to other sprinkler systems in which sprinklers have a nonuniform spacing and apply water to differently sized areas. Evaluations must also account for spatial variation, which occurs as end guns and towers are activated, and as system travel speeds unintentionally vary (e.g., wheel slip).

Many times sprinkler application (precipitation) rates exceed the infiltration rate of the soil, resulting in surface redistribution and, potentially, runoff of applied water. This condition sometimes occurs near the outside of center-pivot circles, since application (precipitation) rates are highest in that area. Such surface redistribution, which can also occur with other sprinkler systems, complicates determination of $D U$. There is an implicit assumption for sprinklers and drip/micro systems that all water that reaches the ground infiltrates close to the point of initial contact. If there is translocation or runoff, $D U_{l q}$ is typically overestimated with current evaluation procedures (e.g., unless, by chance, translocated water improves the distribution uniformity).

Surface-irrigation methods provide the greatest challenge, as can be evidenced by the numerous papers that have been published to describe infiltration. Once an evaluator has chosen

TABLE 4. Typical Locations of Lowest Depths with Various Irrigation Methods

\begin{tabular}{|c|c|c|}
\hline $\begin{array}{l}\text { Irrigation method } \\
\text { (1) }\end{array}$ & $\begin{array}{l}\text { Common location } \\
\text { of lowest depths } \\
\text { (2) }\end{array}$ & $\begin{array}{l}\text { Reason for this location } \\
\text { (3) }\end{array}$ \\
\hline Hand-move sprinkler & The tail end of an uphill lateral. & $\begin{array}{l}\text { Pressure will be lowest at the distant, most uphill end, resulting in lowest flow rates and poor } \\
\text { sprinkler pattern uniformities. }\end{array}$ \\
\hline Drip/micro & $\begin{array}{l}\text { Tail end of the most distant and } \\
\text { uphill lateral. }\end{array}$ & $\begin{array}{l}\text { Pressures are usually lowest at this point. Also, slow velocities during operation and problems } \\
\text { flushing the system to this point may cause an increased incidence of clogging. }\end{array}$ \\
\hline Center pivot sprinkler & Any circular band. & Improper nozzle sizes or plugged nozzles. \\
\hline Border strip & Either end of the strip. & $\begin{array}{l}\text { Very low flow rate and long application time will cause high infiltration at head end; very } \\
\text { high flow rate and short application time may cause a high infiltration at tail end. Actual } \\
\text { effects depend on shape of recession curve and quality of land grading. }\end{array}$ \\
\hline Furrow & $\begin{array}{l}\text { Near the tail end of a wheel-row } \\
\text { furrow. }\end{array}$ & $\begin{array}{l}\text { The wheel rows are more compacted than nonwheel rows. Tail end may have least opportunity } \\
\text { time for infiltration (assuming furrow ends are not blocked). Assumes flow/furrow is ad- } \\
\text { justed for same advance time for wheel- and nonwheel-row furrows. }\end{array}$ \\
\hline Basin & $\begin{array}{l}\text { High spot near farthest point } \\
\text { from water source. }\end{array}$ & This will be last spot covered with water and first to go dry. \\
\hline
\end{tabular}


an infiltration equation, there are numerous techniques available to estimate the constants in such equations; rarely do these evaluation techniques produce identical predictions, even if the coefficients are adjusted to satisfy the volume balance for an irrigation event. In addition, questions of preferential flow through soils, and spatial variability of soil infiltration characteristics, have yet to be answered satisfactorily for evaluators.

Worn or mixed-size sprinkler nozzles are a major source of nonuniformity. Another major reason for nonuniform water application is pressure difference. The effect of known pressure differences can be evaluated if one knows the pressure/flow rate relationship of the emission devices. The following equation is often used for sprinklers and emitters:

$$
Q=c P^{x}
$$

where $Q=$ flow rate; $P=$ line pressure at discharge point; $c$ $=$ a constant that depends on emitter or nozzle geometry and units for $Q$ and $P$; and $x=$ a discharge exponent, usually 0.5 for sprinklers and microsprayers, and between 0.05 and 0.8 for drip.

Likewise, a major factor in nonuniformity with surface irrigation methods is difference in infiltration opportunity times. The following equation is often used to describe the relationship between infiltration opportunity time and the depth infiltrated:

$$
d=k\left(t_{o}\right)^{a}
$$

where $d=$ infiltrated depth; $t_{o}=$ infiltration opportunity time; $k=$ a constant that depends on soil and units for $d$ and $t_{o}$; and $a=$ an infiltration exponent, usually between 0.1 and 0.8 .

One might consider a variation in opportunity time with surface irrigation to be somewhat analogous to a variation in pressure with sprinkler systems. Similarly, a difference in sprinkler nozzle sizes is similar to having different soil types in a field (i.e., as might be represented by a difference in $k$ ).

\section{Components of Uniformity}

As shown in Table 3, consideration of global uniformity for different irrigation systems implies consideration of many components of uniformity, the particular components depending on the particular irrigation method. In field evaluations, it is often convenient to make measurements relating to each component individually, and then to combine these results somehow to determine the global uniformity (Solomon 1985; Burt 1992).

Unfortunately, this is not always done in practice. For example, most hand-move sprinkler systems have been designed by rules of thumb regarding allowable pressure differences, which affect sprinkler flow rates. However, these systems are often evaluated only in terms of catch-can uniformity. Clearly, a global evaluation of uniformity must consider both sprinkler pattern (catch-can) uniformity and pressure distribution (and perhaps other) factors.

An evaluation of $D U$, while providing valuable information regarding the performance of an irrigation system, does not address all aspects of spatial variation of water distribution. $D U$ is only an indication of whether all plant elemental areas receive similar amounts of water. A drip/microirrigation system may have an excellent $D U_{l g}$, yet, for example, only wet $30 \%$ of the potential soil root zone. For agronomic purposes it may be preferable to have a more complete distribution of water across the whole soil surface; such a question is outside the realm of $D U$ measurement. Likewise, on a particular site, a furrow irrigation may have a $D U$ that is high, but attainable only if a large average depth of water is infiltrated. Plants may suffer from water stress if a manager waits until the soil is dry enough to hold the large water depth that must be applied to obtain a high $D U$.

\section{COMBINATION OF UNIFORMITY COMPONENTS}

One method for estimating global distribution uniformity is to multiply the $D U$ s of the individual components:

$$
D U_{a, 0}=\left(D U_{a, 1}\right) \times\left(D U_{a, 2}\right)
$$

where $D U_{a, 1}$ and $D U_{a, 2}=D U_{a}$ for components 1 and 2, respectively; subscript $a=$ field fraction with smallest depths being considered; and $D U_{a, 0}=$ combined $D U_{a}$ considering both components. This equation can be expanded to consider as many components as desired. If all components of uniformity are represented on the right-hand side, the combined $D U_{a, 0}$ is intended to represent the overall or global $D U_{a}$. An example of this type of formulation is the emission uniformity $(E U)$ suggested as a design criterion for microirrigation systems (applicable prior to emitter plugging and wear) (Karmeli and Keller 1974):

$$
E U=\left(1-1.27 \frac{C V_{M}}{\sqrt{n}}\right) \times\left(\frac{Q_{L_{q}}}{Q_{\mathrm{avg}}}\right) 100 \%
$$

in which $C V_{M}=$ manufacturer's coefficient of variation for emitter properties; $n=$ number of emitters per plant; and $Q_{l q}$ and $Q_{\text {avg }}$ represent, respectively, average of low quarter and overall average of emitter discharges calculated from pressure distribution assuming all emitters have same pressure-discharge relationship. Thus, the first factor of this product accounts for emitter manufacturing variability, and the second accounts for system pressure changes.

The advantage of this approach is simplicity. However, simple multiplication of $D U$ components may underestimate the true value of the global $D U$, although errors are minimal for systems with fairly high $D U$. Averages of the low quarter do not always combine in predictable ways, and the proper form for their combination does not always follow the simplicity of (19). For this reason, consideration should be given to a more statistically based approach to combining these components.

Clemmens and Solomon (unpublished, 1997) use statistical procedures to develop equations for global distribution uniformity. They suggest the use of the following relationship for combining uniformity components when the influence of two components on depth is multiplicative:

$$
S D U_{a, 0}=\left[1-\sqrt{\left(1-D U_{a, 1}\right)^{2}+\left(1-D U_{a, 2}\right)^{2}}\right]
$$

Other equations are provided for additive components or for areas that are added.

The strength of this approach is improved accuracy and defensibility. The weakness is that it assumes relatively wellbehaved depth distributions. This equation was derived on the assumption that depth distributions are random and that all the distributions are of the same type (i.e., same $K_{a}$, but not necessarily normally distributed). However, Clemmens and Solomon (unpublished, 1997) showed that this formulation works reasonably well even when the distributions of depths for the components do not have the same shape (and are not normally distributed). Examples are given for surface, sprinkler, and microirrigation. Eq. (20) needs further testing for highly skewed distributions, for example, when some emitters are plugged. No such rigorous testing has been applied to the simplified methods of combining components [i.e., (18) and (19)].

The effects of some irrigation system components on the distribution of water can be well approximated by a normal distribution, for example, microirrigation manufacturing variability, sprinkler overlap patterns, surface irrigation land-leveling precision, and so forth. As previously noted, $K_{l q}=1.27$ for a normal distribution. Values of $K_{a}$ for other low area frac- 
TABLE 5. Values of Statistical Distribution Parameter $K$ for Normal Diatrlbution (Adapted from Nakayama of al. 1979)

\begin{tabular}{c|c}
\hline \hline $\begin{array}{c}\text { Low area (\%) } \\
(1)\end{array}$ & $\begin{array}{c}K \\
(2)\end{array}$ \\
\hline 5 & 2.06 \\
10 & 1.75 \\
15 & 1.55 \\
20 & 1.40 \\
25 & 1.27 \\
30 & 1.16 \\
35 & 1.06 \\
40 & 0.97 \\
45 & 0.88 \\
50 & 0.80 \\
\hline \hline
\end{tabular}

tions are given in Table 5 . The $D U_{a}$ for these normally distributed components can be estimated with (13) from an estimate of the standard deviations of depths resulting from the variations of these components. For example, $D U_{a, 1}$ might represent effects of the manufacturer's emitter variation, described by $C V_{M}$, with one emitter per plant. Then $D U_{l q, 1}=1-1.27 C V_{M}$.

There are many components whose influence on depth is not normally distributed, for example, lateral line pressure variations, infiltration opportunity-time distribution, and so on. For these components we recommend that $D U_{a}$ be computed for the variation in depth associated with this component, assuming all other components remain constant. For our microirrigation example, we calculate water depth for each element area (each emitter in the simplest case), assuming pressures vary and emitter properties remain constant. The average low quarter and $D U_{l q .2}$ are determined directly from these depths (i.e., not from the standard deviation and not from measured emitter flow rates). The resulting values of $D U_{l q, 1}$ and $D U_{l q, 2}$ are then substituted into (20). (This example pertains primarily to design, since global $D U$ for these systems can usually be measured directly in the field.)

\section{Errors in DU Estimation}

Errors in $D U$ estimation can arise from a variety of sources. For example, inaccurate pressure gauges can yield errors with sprinkler and drip/microirrigation systems.

A common and more difficult challenge with surface irrigation methods is estimating soil infiltration. Different evaluation procedures can be based on different infiltration equations or yield different constants in the same infiltration equation, which then results in different estimates of $D U$, even with the same distribution of infiltration opportunity times. These methods typically determine an average infiltration relationship and do not consider soil variability.

Challenges also stem from the diversity of conditions, even within a single field. In surface irrigation systems, estimating opportunity times for an entire field rather than, say, a single furrow is very difficult. In sprinkler and drip/microirrigation systems, pressure-distribution patterns throughout a field are influenced by

- The presence or absence of individual sprinkler pressure regulators

- The topography (flat or hilly)

- The length of laterals (long or short)

- The existence of pressure regulation at the heads of sprinkler laterals or micro-submains or manifolds

- The design logic used to size pipelines downstream of pressure regulators

It is therefore difficult to precisely characterize the pattern of uniformity without a large number of measurements.

With hand-move sprinklers, there are questions regarding the appropriate area over which the sprinkler overlap pattern is to be measured. Research has shown that even in indoor tests, duplicate tests of supposedly identical sprinklers may produce some differences in measured uniformity (Solomon 1979). Furthermore, some evaluation techniques recommend placing catch cans between two sprinklers along a lateral, whereas others recommend placing them between two sets of two sprinklers along a lateral. These two techniques will give very different results.

As discussed in the foregoing, errors may also be introduced when trying to determine a global distribution uniformity from measurements of various $D U$ components. Errors could result from

- Not incorporating all the factors that affect $D U$

- Errors in measurements associated with the various components

- Errors in equations used to combine these components

\section{CONCLUSIONS}

Several important issues have been emphasized in this report.

1. Priority is placed on understanding what happens to applied irrigation water. Once that is known, there are several ratios or terms that can be used to describe irrigation performance. Accurately determining and quantifying water-balance components is not easy to do in a hydrologic system, regardless of scale (e.g., field or basin).

2. A clear distinction is made between water that is consumed and water that is used beneficially. Combinations of these two descriptions make four groupings: water consumed beneficially; water consumed nonbeneficially; nonconsumed water used beneficially; and nonconsumed water not used beneficially. Many existing definitions mix these concepts, creating confusion.

3. It is clear that increasing irrigation efficiency does not necessarily make more water available for other uses. Water availability for other uses can only be increased by decreasing consumption.

4. Efficiency terms, which relate terms in a water balance, are determined after the fact and must consider changes in storage within specified boundaries over a specified interval of time. The implication is that irrigation efficiency cannot be defined for an individual event and that proper specification of the time interval is important for determining useful values of irrigation efficiency.

5. The concept of a reasonable amount of nonbeneficially used water stemming from physical and financial constraints is introduced. Judgment is required to define this category of water use, but the concept reflects the need to be practical. A new term, irrigation sagacity, is defined in (3) to incorporate the concept of beneficially plus reasonably used water and to avoid blurring the meaning of irrigation efficiency. Such concepts are essential for many policy decisions.

6. The difficulty in arriving at accurate estimates of physical quantities in the water balance-a prerequisite for any performance measure - is pointed out, and procedures are recommended in a companion paper for determining the confidence intervals of any performance indicator of interest. For example, with current technology, it may be difficult to determine efficiency values to within $\pm 10 \%$. It is also important to convey to policy makers and regulators that the pertinent water quantities cannot be accurately measured on a large scale without significant cost. 
7. Nonirrigation water sources are purposely excluded from definitions of irrigation performance. The committee believes that including such water would make the definitions more difficult to apply in practice and involve far more judgment. As other sources of water can be categorized by the same hydrologic breakdown, it was chosen not to provide such definitions here. Similarly, definition of performance for uses other than irrigation (e.g., overall farm water management including rainfall) were not included herein.

8. Application efficiency $(A E)$ is defined in terms of a defined target depth or requirement, rather than only in terms of soil water depletion. This more flexible definition allows $A E$ to be more easily adapted for management use.

9. Irrigation uniformity is discussed in terms of its importance in management and the problems associated with measuring the distribution of irrigation water. A framework is provided for making $D U$ more universal and less subject to crop and irrigation system specifics. This framework considers the plant scale, water that influences plant water use but does not infiltrate, and methods for combining multiple influences (i.e., what the plants experience).

10. The average low-quarter depth of the distribution was recommended as an indicator of irrigation performance for typical agricultural applications, due to its practicality and wide acceptance.

11. Performance measures defined herein for evaluating the performance of individual irrigation events assume that the need for water is uniform over the field. These differ from performance measures for overall management, for example, irrigation efficiency, which attempt to take into account the spatial variability in water uses. Existing performance measures for individual events will need to be modified for prescription water application methods that have a nonuniform target.

\section{APPENDIX I. REFERENCES}

ASCE. (1978). "Describing irrigation efficiency and uniformity." J. Irrig. and Drain. Engrg., ASCE, 104(1), 35-41.

Bos, M. G. (1985). "Summary of ICID definitions on irrigation efficiency." ICID Bull., 344(1), 28-35.

Burt, C. M. (1980). "Practical efficiencies for drip irrigation." Pmoc., Calif. Irrig. Inst. Annu. Meeting, Sacramento, Calif.

Burt, C. M. (1983). "Aspects of efficiency." Proc., 1983 IA Tech. Conf., Denver, Colo.

Burt, C. M. (1989). "Irrigation efficiency and uniformity," Proc., IA Short Course on Irrig. Design Prep., Anaheim, Calif.

Burt, C. M., Walker, R. E., and Styles, S. W. (1992). Irrigation system evaluation manual. Irrig. Training and Res. Ctr., California Polytechnic State Univ., San Luis Obispo, Calif.

Christiansen, J. E. (1942). "Irrigation by sprinkling." Bulletin 670, California Agric. Expt. Station, Univ. of Calif., Davis, Calif.

Clemmens, A. J. (1986). "Border irrigation uniformity: Combined effects of infiltration." Trans. ASAE, 29(5), 1314-1319, 1324.

Clemmens, A. J. (1991). "Irrigation uniformity relationships for irrigation system management." J. Irrig. and Drain. Engrg., ASCE, 118(6), $1007-1008$.

Hart, W. E. (1961). "Overhead irrigation pattern parameters." Agric. Engrg., July, 354-355.

Hart, W. E., and Reynolds, W. N. (1965). "Analytical design of sprinkler systems." Trans. ASAE, 8(1), 83-85, 89.

Heermann, D. F., Wallender, W. W., and Bos, M. G. (1990). "Irrigation efficiency and uniformity." Chap. 6 in Management of Farm Irrigation Systems, G. J. Hoffman, T. A. Howell, and K. H. Solomon, eds., American Society of Agricultural Engineers, St. Joseph, Mich., 125-149.

ICID. (1995). Meeting of working group on irrigation performance. Sept., International Commission on Irrigation and Drainage, Rome, Italy.

Jensen, M. E. (1972). "Programming irrigation for greater efficiency."

Optimizing the soil physical envinonment toward greater crop yields, D. Hillel, ed., Academic Press, New York, N.Y., 133-161.

Jensen, M. E. (1993). "The impact of irrigation and drainage on the environment." Sth Gulhati Memorial Lect. International Commission on Irrigation and Drainage, The Hague, The Netherlands.

Karmeli, D., and Keller, J. (1974). Trickle irrigation design. Rain Bird Sprinkler Manufacturing Corp., Glendora, Calif.

Keren, R., and Miyamoto, S. (1990). "Reclamation of saline, sodic, and boron-affected soils." Chap. 19 in Agricultural salinity assessment and management, K. Tanji, ed., ASCE Manual and Rep. on Engrg. Practice No. 71, ASCE, New York, N.Y.

Merriam, J. L., and Keller, J. (1978). Farm irrigation system evaluation: A guide to management. Utah State Univ., Logan, Utah.

Nakayama, F. S., Bucks, D. A., and Clemmens, A. J. (1979). "Assessing trickle emitter application uniformity." Trans. ASAE, 22(4), 816-821.

Solomon, K. H. (1979). "Variability of sprinkler coefficient of uniformity test results." Trans. ASAE, 22(5), 1078-1080, 1086.

Solomon, K. H. (1983). "Irrigation uniformity and yield theory," $\mathrm{PhD}$ thesis, Utah State Univ., Logan, Utah.

Solomon, K. H. (1985). "Global uniformity of trickle irrigation systems." Trans. ASAE, 28(4), 1151-1158.

Wolters, W. (1992). Influences on the efficiency of irrigation water use. Int. Inst. for Land Reclamation and Improvement, Wageningen, The Netherlands.

\section{APPENDIX II. NOTATION}

The following symbols are used in this paper:

$A D_{l q}=$ adequacy of an irrigation;

$A E$ = application efficiency;

$A E_{l q}=$ low-quarter application efficiency:

$B U=$ beneficial use;

$C V=$ coefficient of variation;

$D_{a b d p}=$ average actual depth of beneficial deep percolation in field;

$D_{\text {anbdp }}=$ average actual depth of nonbeneficial deep percolation in field;

$D_{b d p}=$ average depth of beneficial deep percolation in field;

$D_{d p}=$ average actual depth of deep percolation in field

$D_{\text {rbdp }}=$ average required depth of beneficial deep percolation in field;

$D P=$ deep percolation;

$D U=$ distribution uniformity;

$D U_{t q}=$ distribution uniformity using low-quarter depth;

$d_{\text {avg }}=$ average depth of water accumulated in plant element areas;

$d_{b d p}=$ depth of beneficial deep percolation at location;

$d_{d p}=$ local actual depth of deep percolation;

$d_{l q}=$ average low-quarter depth;

$d_{\text {rbdp }}=$ required depth of beneficial deep percolation at location;

$E=$ evaporation;

$E C_{e}=$ electrical conductivity of saturated soil paste extract;

$E P=$ effective precipitation;

$E T=$ evapotranspiration;

$E T_{c}=$ crop evapotranspiration;

$E U=$ emission uniformity;

ICUC = irrigation consumptive use coefficient;

$I E$ = irrigation efficiency;

$I S$ = irrigation sagacity;

$K_{a}=$ parameter related to both distribution type and area fraction, used for $S D U_{a}$ i

$K_{t h}=K_{a}$ for normal distribution, using area fraction of low half;

$K_{l q}=K_{a}$ for normal distribution, using area fraction of low quarter;

$m=$ mean value;

$P=$ pressure

$P A E=$ potential application efficiency;

$P A E_{l q}=$ potential application efficiency of low quarter;

$Q=$ flow rate;

$R O=$ runoff;

$S D U=$ statistically derived estimate of $D U$;

$S D U_{a}=$ statistically derived estimate of $D U$, assuming certain distribution type, $a$;

$s=$ standard deviation;

$T=$ transpiration; and

$U C=$ Christiansen uniformity coefficient. 